\title{
Intracellular Binding Site for a Positive Allosteric Modulator of the Dopamine D1 Receptor ${ }^{\text {S }}$
}

\author{
Xushan Wang, Beverly A. Heinz, Yue-Wei Qian, Joan H. Carter, Robert A. Gadski, \\ Lisa S. Beavers, Sheila P. Little, Charles R. Yang, ${ }^{1}$ James P. Beck, Junliang Hao, \\ John M. Schaus, Kjell A. Svensson, and Robert F. Bruns
}

Lilly Research Laboratories, Eli Lilly \& Co., Indianapolis, Indiana

Received April 3, 2018; accepted August 10, 2018

\begin{abstract}
The binding site for DETQ [2-(2,6-dichlorophenyl)-1-((1S,3R)3-(hydroxymethyl)-5-(2-hydroxypropan-2-yl)-1-methyl-3,4dihydroisoquinolin-2 $(1 H)$-yl)ethan-1-one], a positive allosteric modulator (PAM) of the dopamine D1 receptor, was identified and compared with the binding site for CID 2886111 [N-(6-tert-butyl3-carbamoyl-4,5,6,7-tetrahydro-1-benzothiophen-2-yl)pyridine-4carboxamide], a reference D1 PAM. From D1/D5 chimeras, the site responsible for potentiation by DETQ of the increase in cAMP in response to dopamine was narrowed down to the $\mathrm{N}$-terminal intracellular quadrant of the receptor; arginine-130 in intracellular loop 2 (IC2) was then identified as a critical amino acid based on a human/rat species difference. Confirming the importance of IC2, a $\beta 2$-adrenergic receptor construct in which the IC2 region was replaced with its D1 counterpart gained the ability to respond to
\end{abstract}

\section{Introduction}

Positive allosteric modulators (PAMs) are a promising approach for amplifying physiologic control circuits. A stumbling block in implementing such an approach is the difficulty of finding and optimizing compounds with PAM activity. A better understanding of the binding sites for these drugs should therefore facilitate their discovery. This study describes an intracellular binding site for DETQ [2-(2,6-dichlorophenyl)1-((1S,3R)-3-(hydroxymethyl)-5-(2-hydroxypropan-2-yl)-1-methyl3,4-dihydroisoquinolin-2(1H)-yl)ethan-1-one], a PAM of the dopamine D1 receptor (Beadle et al., 2014; Svensson et al., 2017; Bruns et al., 2018).

\footnotetext{
This work was supported by Eli Lilly \& Co.

${ }^{1}$ Current affiliation: Shanghai Pharma Innovation, Inc., South San Francisco, California.

https://doi.org/10.1124/mol.118.112649.

S This article has supplemental material available at molpharm. aspetjournals.org
}

DETQ. A homology model was built from the agonist-state $\beta 2$-receptor structure, and DETQ was found to dock to a cleft created by IC2 and adjacent portions of transmembrane helices 3 and 4 (TM3 and TM4). When residues modeled as pointing into the cleft were mutated to alanine, large reductions in the potency of DETQ were found for Val119 and Trp123 (flanking the conserved DRY sequence in TM3), Arg130 (located in IC2), and Leu143 (TM4). The D1/D5 difference was found to reside in Ala139; changing this residue to methionine as in the D5 receptor reduced the potency of DETQ by approximately 1000-fold. None of these mutations affected the activity of CID 2886111, indicating that it binds to a different allosteric site. When combined, DETQ and CID 2886111 elicited a supra-additive response in the absence of dopamine, implying that both PAMs can bind to the D1 receptor simultaneously.

The free energy for activation of a receptor by an agonist is derived from the higher affinity of the agonist for the activated conformation of the receptor compared with the inactive or ground conformation. Binding of agonist to the activated state traps the receptor in this state, causing accumulation of activated receptors that then mediate a downstream response. Although the binding site for the agonist is by definition an allosteric site, by convention it is called the orthosteric site to distinguish it from other possible binding sites. If a second allosteric site exists, ligands that bind there can act as positive or negative allosteric modulators (PAMs or NAMs). A PAM has higher affinity for the activated state than the inactive state and will therefore synergize with an orthosteric agonist, increasing its affinity and/or efficacy. In contrast, a NAM has higher affinity for the inactive state than the activated state and will decrease the affinity and/or efficacy of an orthosteric agonist. Although evidence has accumulated that G protein-coupled receptors (GPCRs) can have different activated states that drive different signaling pathways

ABBREVIATIONS: CID 2862078, 6-tert-butyl-2-(thiophene-2-carbonylamino)-4,5,6,7-tetrahydro-1-benzothiophene-3-carboxamide; CID 2886111, $\mathrm{N}$-(6-tert-butyl-3-carbamoyl-4,5,6,7-tetrahydro-1-benzothiophen-2-yl)pyridine-4-carboxamide; CRC, concentration-response curve; DETQ, 2(2,6-dichlorophenyl)-1-((1S,3R)-3-(hydroxymethyl)-5-(2-hydroxypropan-2-yl)-1-methyl-3,4-dihydroisoquinolin-2(1H)-yl)ethan-1-one; DMSO, dimethylsulfoxide; FBS, fetal bovine serum; G418, [(2R,3S,4R,5R,6S)-5-amino-6-[(1R,2S,3S,4R,6S)-4,6-diamino-3-[(2R,3R,4R,5R)-3,5dihydroxy-5-methyl-4-methylaminooxan-2-yl]oxy-2-hydroxycyclohexyl]oxy-2-(1-hydroxyethyl)oxane-3,4-diol; GPCR, G protein-coupled receptor; HEK293, human embryonic kidney 293; IC, intracellular loop; NAM, negative allosteric modulator; NNC-0640, 4-[[(4cyclohexylphenyl)-[(3-methylsulfonylphenyl)carbamoyl]amino]methyl]- $N$-(2H-tetrazol-5-yl)benzamide; PAM, positive allosteric modulator; $\mathrm{RA}$, relative activity ratio (max/EC ${ }_{50}$ ); $\mathrm{SCH} 23390,7$-chloro-3-methyl-1-phenyl-1,2,4,5-tetrahydro-3-benzazepin-8-ol; TM, transmembrane helix. 
(Kenakin and Christopoulos, 2013), such "biased signaling" has so far not been observed with D1 PAMs (Svensson et al., 2017) and we will therefore refer to a single activated conformation in describing the results of this study.

Although some allosteric sites may host naturally occurring regulatory molecules (e.g., the glycine binding site of the $N$-methyl-D-aspartic acid receptor), this does not have to be the case. Any site that changes its configuration between the activated and ground states may be subject to differential binding of a ligand, which may then act as a PAM or NAM. Thus, a site that plays a purely structural role in nature can be co-opted as an allosteric site in pharmacology; in agreement with this, endogenous ligands have not been found for many well known allosteric sites, such as the barbiturate and benzodiazepine sites on the GABA-A receptor.

PAMs of GPCRs have been known for over 2 decades (Bruns and Fergus, 1990; Nemeth et al., 1998), but only recently has the diversity of potential allosteric sites on these receptors been recognized (Congreve et al., 2017). For class A GPCRs, the most well documented site for PAMs and NAMs is the vestibule (Kruse et al., 2013), the site on the extracellular face between extracellular loops 2 and 3 through which orthosteric ligands must pass before entering the deeper orthosteric site situated between the transmembrane (TM) helices. In class $\mathrm{C}$ GPCRs, whose orthosteric sites are located in a separate extracellular domain, allosteric sites are often located in the interior of the TM barrel in roughly the same location as the orthosteric site in class A GPCRs (Conn et al., 2014).

Other GPCR allosteric sites are located near the intracellular face. The glucagon receptor NAM NNC-0640 (4-[[(4cyclohexylphenyl)-[(3-methylsulfonylphenyl)carbamoyl]amino] methyl]- $N$-(2H-tetrazol-5-yl)benzamide) binds to a cleft on the outward (lipid-facing) side of TM helices 6 and 7 near the cytoplasmic face (Zhang et al., 2017), as do PAMs and NAMs of the glucagon-like peptide 1 receptor (Nolte et al., 2014; Bueno et al., 2016; Song et al., 2017). NAMs of the $\beta 2$-adrenergic receptor (Liu et al., 2017), CC chemokine receptor 2 (Zheng et al., 2016), and CC chemokine receptor 9 (Oswald et al., 2016) bind to an inward-facing site at the cytoplasmic ends of TMs 1 , 2,6 , and 7 , where they compete sterically with $\mathrm{G}$ protein.

Finally, the dopamine D1 PAM “compound B" was shown by site-directed mutagenesis to bind to a cleft in intracellular loop 2 (IC2) (Lewis et al., 2015), a part of the receptor involved in receptor activation and G-protein coupling. In this study, we find that the D1 PAM DETQ also binds to this site. Using chimeric receptors and mutation of individual amino acids, we identify residues important for activity of DETQ at the D1 receptor and for selectivity versus the closely related D5 and $\beta 2$ receptors. As a comparator, we also studied CID 2886111 [ $N$-(6-tert-butyl-3-carbamoyl-4,5,6,7-tetrahydro-1-benzothiophen2-yl)pyridine-4-carboxamide], a D1 PAM from a series discovered by the Sibley group (Luderman et al., 2016). We find that CID 2886111 is unaffected by alterations to IC2, indicating that it binds to a different, as yet unidentified, site. Interestingly, although DETQ and CID 2886111 separately only have slight allo-agonist activity, the combination of the two in the absence of dopamine produces a much larger cAMP response than either PAM alone, as is predicted if both PAMs stabilize the same activated conformation by binding to separate sites. These results imply the presence of multiple allosteric sites on the D1 receptor and therefore multiple opportunities for discovery of allosteric modulators of GPCRs.

\section{Materials and Methods}

Materials. DETQ was synthesized as previously described (Beadle et al., 2014). CID 2886111 was purchased from ChemBridge (San Diego, CA). Dopamine and other pharmacological reagents were purchased from Sigma (St. Louis, MO). Sources of other reagents are provided in individual protocols.

Construction of D1 Chimeras and Mutants. Human DRD1 (RefSeq accession no. NM_000794.3) cDNA was purchased from Open Biosystems (Huntsville, AL) (cat. no. MHS1010-98052134, clone ID 30915514, accession no. BC074978). Human DRD5 (RefSeq accession no. NM_000798.4) cDNA was purchased from Thermo Scientific (Waltham, MA) (cat. no. MHS6278-202830153, clone ID 3928370, accession no. BC009748). Human ADRB2 cDNA was purchased from Open Biosystems (cat. no. MHS1001-9025040, accession no. BC073856). The various mutants and chimeras were generated either by polymerase chain reaction-based mutagenesis using the above wild-type cDNA clones as templates or by gene synthesis at GenScript (Piscataway, $\mathrm{NJ})$. The nucleotide sequences encoding full-length wild-type, mutants, and chimeras were inserted into pcDNA3.1hyg or pJTI R4 CMV-TO (Life Technologies, Carlsbad, CA) and verified by DNA sequencing.

Switchover points for all chimeras are described in Supplemental Table 1.

Protocols for Receptor Expression. For transient transfection, wild-type receptors and mutants were generated by polymerase chain reaction and chimeras were created by DNA synthesis. DNA was then cloned into the pcDNA3.1 vector and was transiently transfected using FuGENE HD (Promega, Madison, WI) into human embryonic kidney 293 (HEK293) cells. Transfected cells were cultured in Dulbecco's modified Eagle's medium with high glucose supplemented with 5\% heat inactivated, dialyzed fetal bovine serum (FBS), $1 \mathrm{mM}$ sodium pyruvate, $20 \mathrm{mM}$ HEPES, and $2 \mathrm{mM} \mathrm{L}$-glutamine at $37^{\circ} \mathrm{C}$ in an atmosphere containing $5 \% \mathrm{CO}_{2}$ for 48 hours. Cells were harvested and suspended in freeze media [FBS with $6 \%$ dimethylsulfoxide (DMSO)] at $10^{7}$ cells $/ \mathrm{ml}$, and aliquots were stored in liquid nitrogen.

Stable cell lines were established using the Jump-In T-REx HEK293 Retargeting Kit (Life Technologies). Wild-type, mutants, and chimeras were either directly cloned into pJTI R4 CMV-TO vector or subcloned from pcDNA3.1, then transfected using FuGENE HD into Jump-In T-REx HEK293 cells. Transfected cells were selected using $2.5 \mathrm{mg} / \mathrm{ml}$ G418 [ $(2 R, 3 S, 4 R, 5 R, 6 S)$-5-amino-6-[( $1 R, 2 S, 3 S, 4 R, 6 S)$-4,6-diamino3 -[(2R,3R,4R,5R)-3,5-dihydroxy-5-methyl-4-methylaminooxan-2-yl] oxy2-hydroxycyclohexyl] oxy-2-(1-hydroxyethyl)oxane-3,4-diol] for 10-14 days. Stable cells were induced using $1 \mu \mathrm{g} / \mathrm{ml}$ doxycycline for $24-48$ hours, then harvested and suspended in freeze media (FBS with 6\% DMSO) at $10^{7} \mathrm{cells} / \mathrm{ml}$, and aliquots were stored in liquid nitrogen.

Measurement of cAMP Response. For experiments in stable cell lines, DETQ and CID 2886111 were diluted in DMSO and dispensed into assay plates (ProxiPlate-384 Plus; PerkinElmer, Waltham, MA) using acoustic dispensing (ECHO; Labcyte, San Jose, CA). To each well containing compound or DMSO blank was added $5 \mu$ l STIM buffer (Hanks' balanced salt solution supplemented with $0.1 \%$ bovine serum albumin, $20 \mathrm{mM}$ HEPES, $500 \mu \mathrm{M}$ 3-isobutyl-1-methylxanthine, and $100 \mu \mathrm{M}$ ascorbic acid) containing a $2 \times \mathrm{EC}_{20}$ concentration of dopamine, followed by cells $(2000$ cells/well) in $5 \mu \mathrm{l}$ STIM. The final DMSO concentration was $0.8 \%$. Plates were incubated at room temperature for a total reaction time of 60 minutes. cAMP production was quantified using homogeneous time-resolved fluorescence detection (Cisbio, Bedford, MA) according to the vendor instructions: lysis buffer containing anti-cAMP cryptate ( $5 \mu \mathrm{l})$ and D2-conjugate ( $5 \mu \mathrm{l})$ was added to the wells, plates were incubated for an additional 60-90 minutes, and timeresolved fluorescence was detected using an EnVision plate reader (PerkinElmer). Experiments in transiently transfected cells were carried out as described above except that each well contained 6000 cells, all aqueous additions were in a volume of $10 \mu \mathrm{l}$, the final volume of the incubation was $20 \mu \mathrm{l}$, dilutions were carried out with an automated pipetting station, and the final compound dispensing step used a Pin Tool (Hamilton, Reno, NV) (100 nl volume). 
Fluorescence data were converted to cAMP concentrations using a cAMP standard curve. For potentiator-mode concentration-response curves (CRCs), results for each construct were expressed as the percentage of the window between an $\mathrm{EC}_{20}$ concentration of dopamine alone and the maximum response to dopamine in that construct. This normalization was carried out separately for each plate, and individual data points from six or more plates (representing replicates from at least 3 separate days) were merged into a single GraphPad data table (GraphPad Inc., La Jolla, CA) for each experiment. The potency of dopamine varied up to 60 -fold between different constructs, presumably due to effects of the mutations on coupling or expression. For this reason, the $\mathrm{EC}_{20}$ concentration of dopamine was determined separately for each construct (Supplemental Fig. 1; Supplemental Tables 2-4).

The Jump-In system integrates the gene to be expressed at a single site that is controlled by a tetracycline-inducible cytomegalovirus promotor, resulting in high expression. $B_{\max }$ values for wild-type D1, the V119A mutant, and the W123A mutant in 3H-SCH23390 (7-chloro-3methyl-1-phenyl-1,2,4,5-tetrahydro-3-benzazepin-8-ol) binding were $6.0 \pm 0.3,8.3 \pm 0.2$, and $4.7 \pm 0.2 \mathrm{pmol} / \mathrm{mg}$ protein, respectively, compared with $0.36 \pm 0.02$ for the $\mathrm{hD} 1$ cell line used in the original characterization of DETQ (Svensson et al., 2017). Although allo-agonist activity of DETQ is greater in the high-expression Jump-In D1 line, potentiator activity of DETQ is essentially the same regardless of receptor expression level (Wang and Heinz, unpublished data), in agreement with the conclusions from a previous study of a series of metabotropic glutamate receptor 5 PAMs (Noetzel et al., 2012).

Curve-Fitting Analysis. For each construct/PAM combination, a single curve was fit to data that were normalized and merged as described above. cAMP values were initially fit to a four-parameter logistic equation using GraphPad software (version 7). Fitted bottom values were consistently found to fall within the range of $\pm 2 \%$ in all mutant and chimera experiments; based on this result, the bottom was fixed to $0 \%$ for final curve generation and analysis. In the experiment investigating interactions between the two PAMs (see Fig. 5), the bottom of the CRC for one PAM depended on the concentration of the other, and the bottom was therefore allowed to vary freely in this analysis.

The S.E. for the best-fit value of each curve-fitting parameter was calculated as described in the GraphPad 7 Curve Fitting Guide:

$$
\text { S.E. }\left(\mathrm{P}_{i}\right)=\operatorname{sqrt}(\mathrm{SS} \bullet \mathrm{DF}) \bullet \operatorname{Cov}(i, i)
$$

where $\mathrm{P}_{i}$ is the $i$ th parameter, $\mathrm{SS}$ is the sum of squared residuals, $\mathrm{DF}$ is degrees of freedom (number of data points minus number of fitted parameters), and $\operatorname{Cov}(i, i)$ is the $i$ th diagonal term of the covariance matrix.

The S.E. of the $\log \mathrm{EC}_{50}$ provided by GraphPad was converted to the S.E. of the untransformed (linear) $\mathrm{EC}_{50}$ by the following equation:

$$
\text { S.E.linear }=\ln (10) \bullet \mathrm{EC}_{50} \bullet \mathrm{S} . \mathrm{E}_{\cdot \log } .
$$

Fitting of Incomplete Curves. In a few constructs in which potency of the PAM was very low, only the initial rising part of the curve was measurable. If the data points do not begin to turn down into a plateau, the relative activity ratio (RA) (see the Results) is still well defined, since it depends only on the initial slope; however, the $\mathrm{EC}_{50}$ and top cannot be separately determined, since any two values in the same ratio will fit the same initial slope. In this situation, a twostep procedure was followed to achieve a stable fit. First, the Hill coefficient was fixed to 1 ; this was supported by the observation that fully defined curves consistently had Hill slopes around 1 (Supplemental Table 2). For three data sets that showed a small degree of downturn at higher concentrations, this resulted in well defined $\mathrm{EC}_{50}$ and top values (see Figs. 7 and 8). For two other data sets (see Fig. 8), the Hill coefficient was fixed to 1 and the top was fixed to $100 \%$, providing a well defined $\mathrm{EC}_{50}$ value for calculation of $\mathrm{RA}$.

Construction of a Homology Model Based on an AgonistState Crystal Structure of the $\boldsymbol{\beta 2}$-Adrenergic Receptor. The $\beta 2$ agonist-state crystal structure 3p0g (Rasmussen et al., 2011a) was imported into the Prime module of the Schrödinger software suite (2011 version; Schrödinger Software, New York, NY) and the ligand and nano-antibody structures were deleted. The human D1 receptor sequence was aligned with the $\beta 2$ sequence and a homology model was constructed using the Structure Prediction Wizard in Prime. There were no insertions or deletions in TM3, IC2, or TM4. The possibility that the IC2 loop could function as a ligand binding site was confirmed using Schrödinger SiteMap.

A simplified analog of DETQ with the 3- and 5-position groups deleted was docked into the IC2 cleft using Schrödinger Glide. In initial docking poses, the ligand consistently adopted a conformation in which the dichlorophenyl ring was nearly coplanar with the tetrahydroisoquinoline ring. In contrast, studies of the ligand alone indicated a strong energetic preference for the dichlorophenyl ring to be nearly perpendicular to the tetrahydroisoquinoline ring, with a prohibitive energetic penalty for coplanarity. Based on this result, the ligand was redocked in its low-energy conformation using the Schrödinger induced-fit protocol with flexible protein and rigid ligand. The ligand was able to fit into the IC2 cleft in several different orientations, and the final pose (see Supplemental Fig. 2 for the Protein Data Bank file) was chosen for its ability to accommodate substitution at the 3- and 5-positions, in agreement with known structure-activity relationships (Beadle et al., 2014). Finally, the 3- and 5-position groups of DETQ were added to the docked structure and the protein-ligand complex was optimized using Prime.

\section{Results}

D1 PAMs. The main purpose of this study was to identify and characterize the binding site for DETQ (Fig. 1), a novel D1 PAM from a series of acyl-tetrahydroisoquinolines (Beadle et al., 2014; Svensson et al., 2017; Bruns et al., 2018). DETQ is a potent allosteric potentiator at the human D1 receptor $\left(\mathrm{EC}_{50}, 5.8 \mathrm{nM}\right)$ with 30 -fold lower activity at the rat D1 receptor and more than 1000 -fold lower activity at the human D5 receptor.

In a study of this kind, it would be helpful to have a comparator compound from an unrelated chemical series, preferably one that bound to a different site. We have used CID 2886111 (Fig. 1) for this purpose. We identified CID 2886111 from its close structural similarity to CID 2862078 [6-tert-butyl-2-(thiophene-2-carbonylamino)-4,5,6,7-tetrahydro1-benzothiophene-3-carboxamide], which was reported to be active in a D1 PAM assay by the Sibley group at the National Institutes of Health (https://pubchem.ncbi.nlm.nih.gov/bioassay/ 504651\#section $=$ Data-Table) $($ Luderman et al., 2016). As

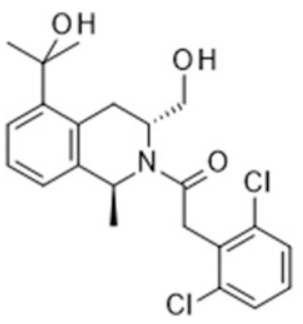

DETQ

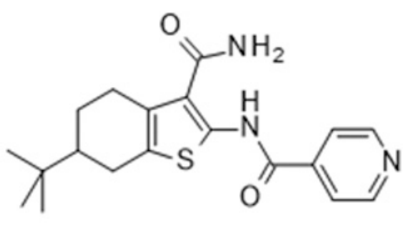

\section{CID 2886111}

Fig. 1. Structures of DETQ and CID 2886111. The structure of CID 2862078 (the original screening hit reported in PubChem by the Sibley group) is identical to that of CID 2886111 except that the 4-pyridyl group is replaced with a 2-thienyl. CID 2886111 is the same compound as the D1 PAM MLS6585 (PubChem MLS000666585) (Luderman et al., 2016, 2018). 


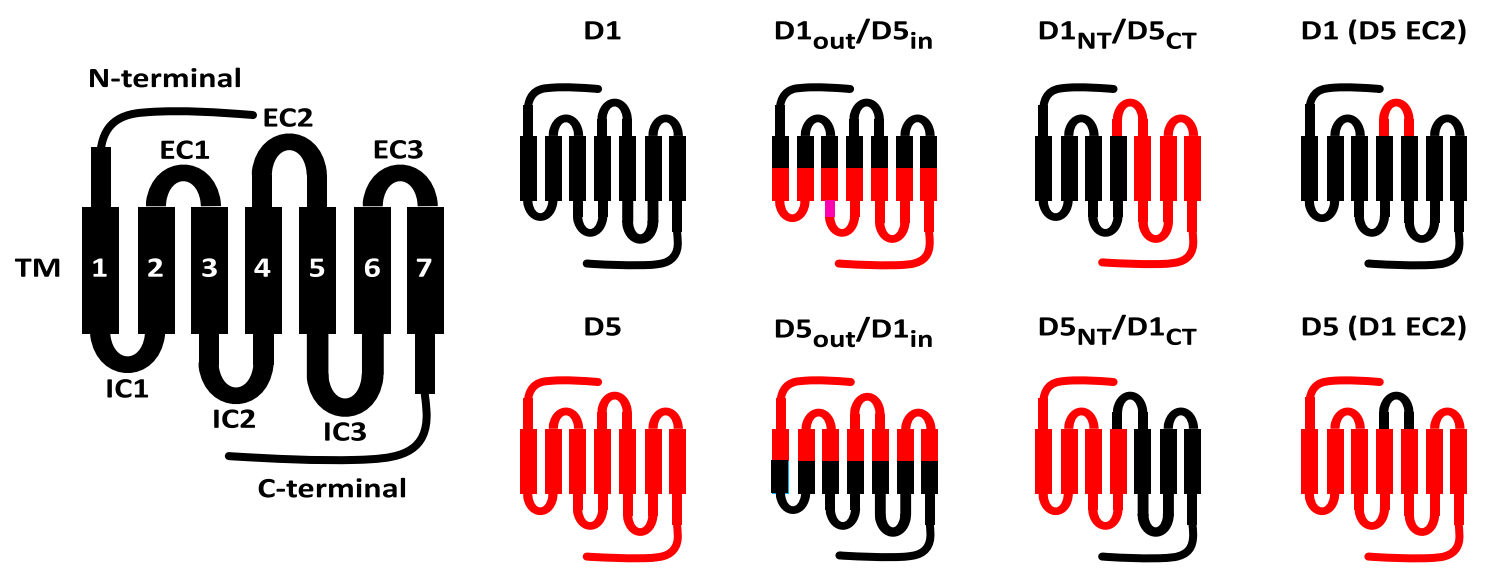

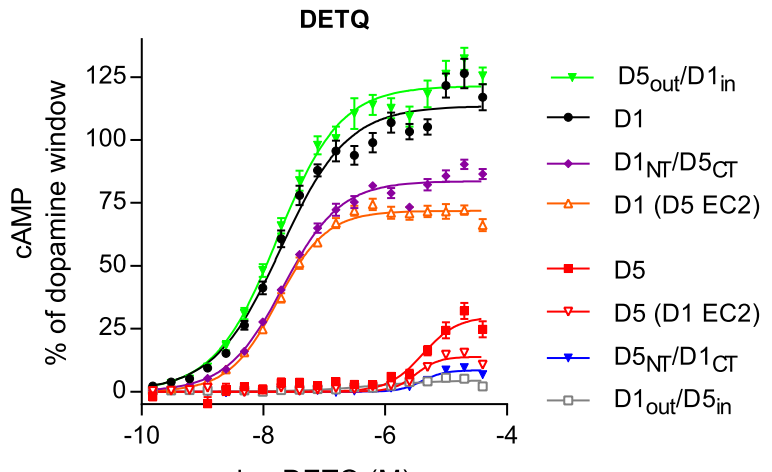

$\log$ DETQ (M)

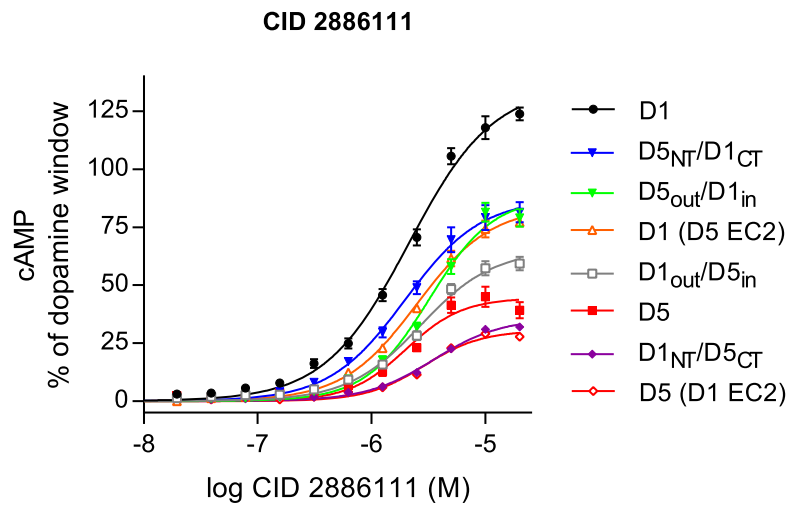

$\log$ CID $2886111(\mathrm{M})$

\begin{tabular}{|c|c|c|c|c|c|c|c|c|c|c|c|c|c|c|c|c|c|c|c|c|}
\hline \multirow{3}{*}{$\begin{array}{l}\text { chimera } \\
\text { D1 }\end{array}$} & \multicolumn{10}{|c|}{ DETQ } & \multicolumn{10}{|c|}{ CID 2886111} \\
\hline & \multicolumn{3}{|c|}{ EC50 (nM) } & \multicolumn{3}{|c|}{$\begin{array}{l}\text { top (\% of DA } \\
\text { window) }\end{array}$} & \multicolumn{3}{|c|}{$\begin{array}{c}\text { relative } \\
\text { activity (X } \\
1000)\end{array}$} & \multirow{2}{*}{$\begin{array}{r}\text { RA as \% } \\
\text { of wild- } \\
\text { type D1 } \\
100\end{array}$} & \multicolumn{3}{|c|}{ EC50 (nM) } & \multicolumn{3}{|c|}{$\begin{array}{l}\text { top (\% of DA } \\
\text { window) }\end{array}$} & \multicolumn{3}{|c|}{$\begin{array}{c}\text { relative } \\
\text { activity (X } \\
1000)\end{array}$} & \multirow{2}{*}{$\begin{array}{r}\text { RA as \% } \\
\text { of wild- } \\
\text { type D1 } \\
10 C\end{array}$} \\
\hline & 19.3 & \pm & 1.8 & 114 & \pm & 2 & 5900 & \pm & 600 & & 1860 & \pm & 90 & 128 & \pm & 2 & 69 & \pm & 4 & \\
\hline D5 & 4200 & \pm & 1000 & 30 & \pm & 3 & 7.2 & \pm & 1.9 & 0.12 & 1740 & \pm & 160 & 40 & \pm & 1 & 23 & \pm & 2 & 33 \\
\hline$D 1_{\text {out }} / D 5_{\text {in }}$ & 580 & \pm & 370 & 4.5 & \pm & 0.7 & 7.7 & \pm & 5.1 & 0.13 & 2300 & \pm & 130 & 60 & \pm & 1 & 26 & \pm & 2 & 38 \\
\hline$D 5_{\text {out }} / D 1_{\text {in }}$ & 16.9 & \pm & 1.4 & 121 & \pm & 2 & 7200 & \pm & 600 & 122 & 2800 & \pm & 100 & 80 & \pm & 2 & 29 & \pm & 2 & 42 \\
\hline $\mathrm{D} 1_{\mathrm{NT}} / \mathrm{D} 5{ }_{\mathrm{CT}}$ & 21.3 & \pm & 1.2 & 84 & \pm & 1 & 3900 & \pm & 200 & 67 & $3100=$ & \pm & 200 & 33 & \pm & 1 & 10.7 & \pm & 0.6 & 15.6 \\
\hline $\mathrm{D} 5 \mathrm{NT}_{\mathrm{NT}} / \mathrm{D} 1_{\mathrm{CT}}$ & 4100 & \pm & 440 & 8.5 & \pm & 0.4 & 2.1 & \pm & 0.3 & 0.04 & 1690 & \pm & 120 & 81 & \pm & 2 & 48 & \pm & 3 & 70 \\
\hline D1 (D5 EC2) & 17.1 & \pm & 1.0 & 72 & \pm & 1 & 4200 & \pm & 200 & 71 & 2300 & \pm & 100 & 81 & \pm & 1 & 35 & \pm & 2 & 50 \\
\hline D5 (D1 EC2) & 3200 & \pm & 320 & 13.8 & \pm & 0.6 & 4.3 & \pm & 0.5 & 0.07 & 2500 & \pm & 200 & 27 & \pm & 1 & 10.9 & \pm & 0.7 & 15.9 \\
\hline \multicolumn{2}{|c|}{$\begin{array}{l}\text { color code for RA as } \\
\% \text { of wild-type }\end{array}$} & & & & & & & & & & & & & & & & & & & \\
\hline \multicolumn{21}{|l|}{30 to 300} \\
\hline \multicolumn{21}{|l|}{3 to 30} \\
\hline$<3$ & & & & & & & & & & & & & & & & & & & & \\
\hline
\end{tabular}

Fig. 2. Potentiation of the cAMP response to an $\mathrm{EC}_{20}$ concentration of dopamine by DETQ and CID 2886111 in D1/D5 chimeras. Values are best-fit parameters \pm S.E. $(n=8)$ from nonlinear least-squares curve-fitting to a four-parameter model with the bottom of the dopamine window fixed to zero. Additional details including Hill coefficients and $\mathrm{EC}_{20}$ dopamine concentrations are provided in Supplemental Table 2. EC, extracellular loop.

described below, CID 2886111 binds to a separate site from DETQ, and functional data imply that DETQ and CID 2886111 can bind to the D1 receptor simultaneously.
D1/D5 Chimeras. A first step toward exploring the binding site for DETQ would be to identify its approximate location on the D1 receptor. Based on the $>1000$-fold preference of 
DETQ

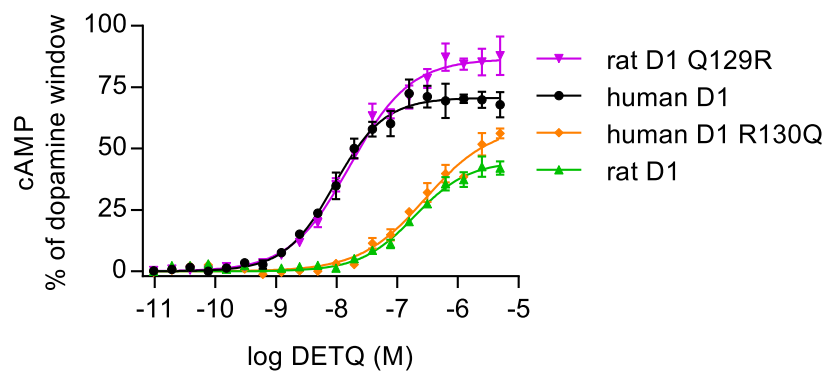

CID 2886111

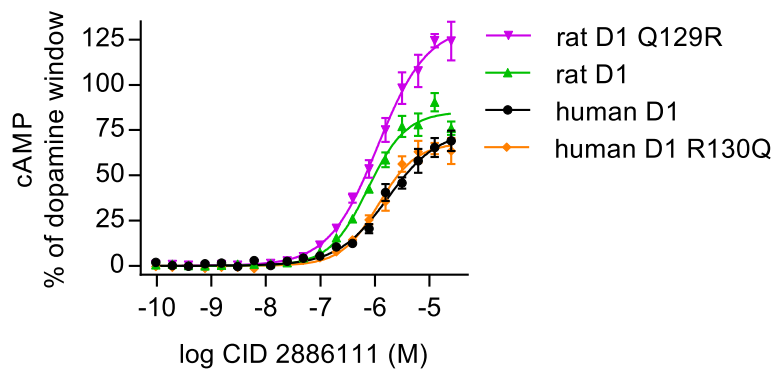

\begin{tabular}{|c|c|c|c|c|c|c|c|c|c|c|c|c|c|c|c|c|c|c|c|c|}
\hline \multirow{3}{*}{$\begin{array}{l}\text { mutant } \\
\text { human D1 }\end{array}$} & \multicolumn{10}{|c|}{ DETQ } & \multicolumn{10}{|c|}{ CID 2886111} \\
\hline & \multicolumn{3}{|c|}{$\mathrm{EC50}(\mathrm{nM})$} & \multicolumn{3}{|c|}{$\begin{array}{c}\text { top (\% of DA } \\
\text { window) }\end{array}$} & \multicolumn{3}{|c|}{$\begin{array}{l}\text { relative activity } \\
\quad(X 1000)\end{array}$} & \multirow{2}{*}{$\begin{array}{c}\text { RA as \% of } \\
\text { wild-type } \\
\text { D1 } \\
100\end{array}$} & \multicolumn{3}{|c|}{ EC50 (nM) } & \multicolumn{3}{|c|}{$\begin{array}{c}\text { top (\% of DA } \\
\text { window) }\end{array}$} & \multicolumn{3}{|c|}{$\begin{array}{c}\text { relative } \\
\text { activity (X } \\
1000)\end{array}$} & $\begin{array}{c}\text { RA as \% of } \\
\text { wild-type } \\
\text { D1 }\end{array}$ \\
\hline & 9.2 & \pm & 1.0 & 71 & \pm & 2 & 7700 & \pm & 900 & & 1820 & \pm & 480 & 76 & \pm & 7 & 42 & \pm & 12 & 100 \\
\hline rat D1 & 192 & \pm & 29 & 45 & \pm & 2 & 230 & \pm & 40 & 3.0 & 940 & \pm & 110 & 94 & \pm & 4 & 100 & \pm & 12 & 239 \\
\hline $\mathrm{hD} 1 \mathrm{R} 130^{\mathrm{IC2} .3} \mathrm{Q}$ & 290 & \pm & 60 & 59 & \pm & 4 & 200 & \pm & 40 & 2.7 & 1320 & \pm & 190 & 72 & \pm & 4 & 54 & \pm & 8 & 130 \\
\hline rat D1 Q129 ${ }^{1 C 2.3} R$ & 16.8 & \pm & 1.8 & 87 & \pm & 2 & 5200 & \pm & 600 & 67 & 1220 & \pm & 190 & 136 & \pm & 7 & 111 & \pm & 18 & 265 \\
\hline \multicolumn{2}{|c|}{$\begin{array}{l}\text { color code for RA as \% of } \\
\text { wild-type }\end{array}$} & & & & & & & & & & & & & & & & & & & \\
\hline \multicolumn{21}{|c|}{30 to 300} \\
\hline \multicolumn{21}{|l|}{3 to 30} \\
\hline$<3$ & & & & & & & & & & & & & & & & & & & & \\
\hline
\end{tabular}

Fig. 3. Effect of the R130Q mutation on the potency of DETQ and CID 2886111 in the presence of an $\mathrm{EC}_{20}$ concentration of dopamine. Q129R is the reverse mutation in the rat D1 receptor. All experiments were carried out using transient expression. Values are best-fit parameters \pm S.E. $(n=6)$ from nonlinear least-squares curve-fitting to a four-parameter model with the bottom of the dopamine window fixed to zero. Additional details including Hill coefficients and $\mathrm{EC}_{20}$ dopamine concentrations are provided in Supplemental Table 2.

DETQ for the D1 receptor over the D5, we replaced regions of the D1 receptor with their D5 counterparts (unless otherwise stated, all D1, D5, and $\beta 2$ receptor constructs refer to the human sequences). By switching out large domains, it should be possible to narrow down the binding site without any prior knowledge of its location. Four chimeras were designed, each replacing about half of the D1 receptor with its D5 counterpart. The first two replaced either the $\mathrm{N}$-terminal or $\mathrm{C}$-terminal half of the $\mathrm{D} 1$ receptor with the $\mathrm{D} 5$ sequence, with the dividing line located between His $164^{4.66}$ and Lys $165^{4.67}$ at the C-terminal end of TM4 [see Ballesteros and Weinstein (1995) for the residue numbering convention; following the GPCRdb database, we define the last residue of TM3 as Ser $127^{3.56}$ and the first residue of TM4 as Thr $136^{4.38}$ ]. Two other chimeras replaced either the extracellular or intracellular half of the D1 receptor with the D5 sequence, with the seven switchover points occurring in the middle of each TM segment (see Supplemental Table 1 for the exact locations of the switchover points). Finally, to identify vestibule binders, two additional chimeras swapped out only extracellular loop 2, leaving the rest of the receptor either D1 or D5.

For each construct, a CRC of each PAM for accumulation of cAMP was carried out in the presence of an $\mathrm{EC}_{20}$ concentration of dopamine (Fig. 2). The RA (Ehlert, 2005; Kenakin, 2017), calculated as the fitted top divided by the $\mathrm{EC}_{50}$ value, was used as a single measure of potency. If the Hill coefficient is near 1 , as seen for the majority of curves in this study (Supplemental Table 2), RA is equivalent to the initial slope of the CRC when plotted on a linear scale. The effect of an experimental intervention such as receptor mutagenesis is conveniently expressed as intrinsic RA (Ehlert, 2005), defined in our study as RA of the mutant construct as a percentage of the RA for the wild-type receptor.

In this study, DETQ was about 1000 -fold less potent at the D5 receptor than at the D1. The constructs in which the $\mathrm{N}$-terminal half or the intracellular half of the D1 receptor were replaced with their D5 counterparts showed a similar loss of affinity for DETQ, whereas the other two half-chimeras showed activity similar to wild-type D1. These results indicate that the binding site for DETQ is in the N-terminal intracellular portion of the receptor.

From the above information, it is possible to deduce the amino acid responsible for the human/rat affinity difference, and hence the location of the binding site for DETQ. The only amino acid in the $\mathrm{N}$-terminal intracellular portion of the receptor that differs between rat and human is arginine-130 $\left(A r g 130{ }^{\mathrm{IC} 2.3}\right.$ ) (Monsma et al., 1990; Zhou et al., 1990), implying that the binding site is located in IC2. This location was previously reported as the binding site for the D1 PAM "compound B" (Lewis et al., 2015). This finding is also in agreement with results of human/rat chimera studies carried out at Lilly early in the D1 project (Gadski, Beavers, Little, Yang, and Bruns, unpublished data). Experiments confirming that an R130Q mutation accounts for the human/rat species difference are described below.

CID 2886111 had nearly the same affinity at the D5 receptor as the D1, although the maximum D5 response was only about 
D1

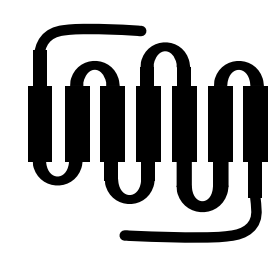

DETQ

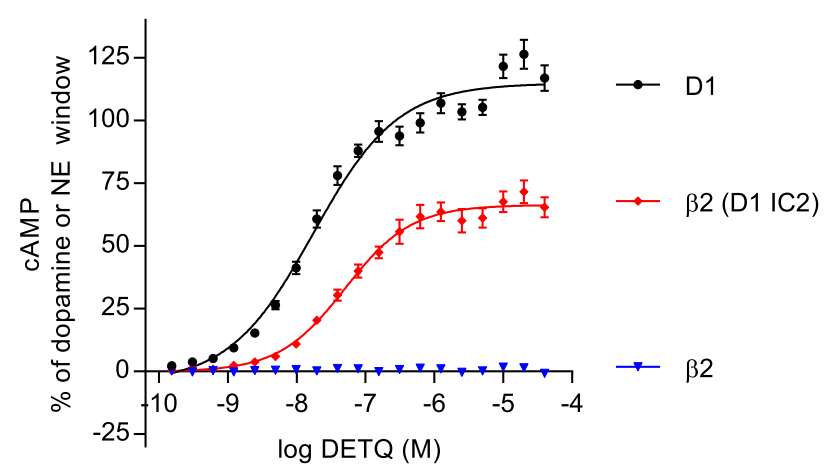

B2

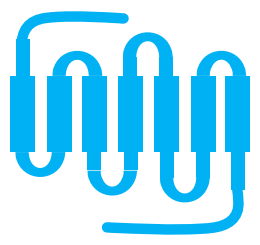

B2 (D1 IC2)

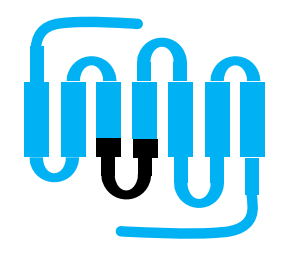

CID 2886111

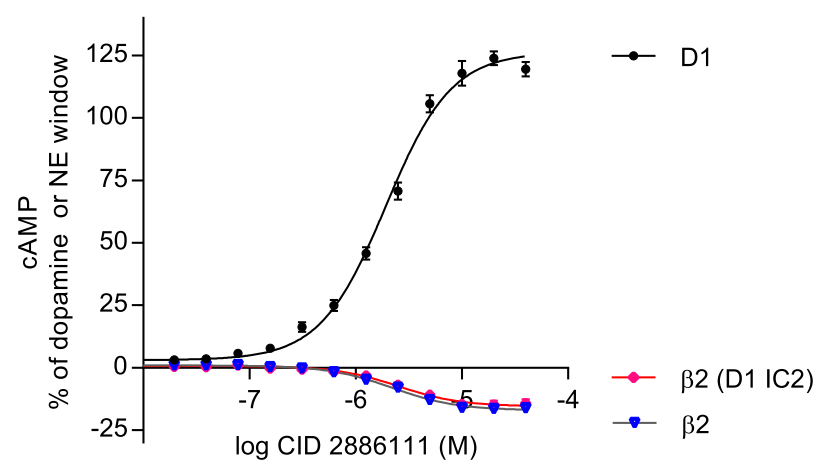

\begin{tabular}{|c|c|c|c|c|c|c|c|c|c|c|c|c|c|c|c|c|c|c|c|c|}
\hline \multirow{3}{*}{$\begin{array}{l}\text { chimera } \\
\text { D1 }\end{array}$} & \multicolumn{10}{|c|}{ DETQ } & \multicolumn{10}{|c|}{ CID 2886111} \\
\hline & \multicolumn{3}{|c|}{ relative EC50 } & \multicolumn{3}{|c|}{ top } & \multicolumn{3}{|c|}{$\begin{array}{l}\text { relative activity } \\
(\text { (X 1000) }\end{array}$} & \multirow{2}{*}{$\begin{array}{c}\text { RA as \% of } \\
\text { wild-type } \\
\text { D1 } \\
100\end{array}$} & \multicolumn{3}{|c|}{ relative EC50 } & \multicolumn{3}{|c|}{ top } & \multicolumn{3}{|c|}{$\begin{array}{c}\text { relative } \\
\text { activity (X } \\
1000)\end{array}$} & \multirow{2}{*}{$\begin{array}{c}\text { RA as \% of } \\
\text { wild-type } \\
\text { D1 } \\
100\end{array}$} \\
\hline & 19.3 & \pm & 1.8 & 114 & \pm & 2 & 5900.0 & \pm & 600.0 & & 1860 & \pm & 90 & 128 & \pm & 2 & 69 & \pm & 4 & \\
\hline$\beta 2$ & $>10000$ & & & $<10$ & & & $<1$ & & & $<0.02$ & 2400 & \pm & 200 & -16.8 & \pm & 0.5 & antag & & & antag \\
\hline$\beta 2$ (D1 IC2) & 51 & \pm & 6 & 66 & \pm & 1 & 1300.0 & \pm & 160.0 & 22 & 2700 & \pm & 300 & -15.3 & \pm & 0.7 & antag & & & antag \\
\hline \multicolumn{2}{|c|}{$\begin{array}{c}\text { color code for RA as } \\
\% \text { of wild-type }\end{array}$} & & & & & & & & & & & & & & & & & & & \\
\hline \multicolumn{21}{|c|}{30 to 300} \\
\hline \multicolumn{21}{|l|}{3 to 30} \\
\hline$<3$ & & & & & & & & & & & & & & & & & & & & \\
\hline
\end{tabular}

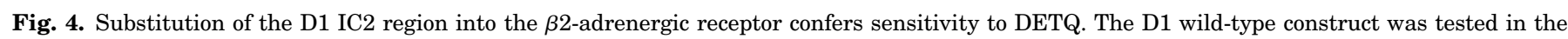

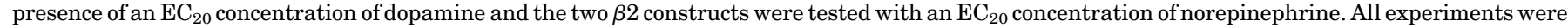

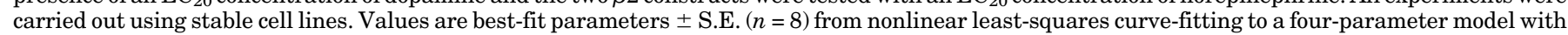

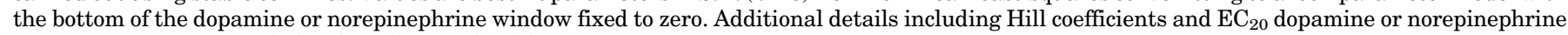
concentrations are provided in Supplemental Table 2.

one-third of the D1 response (Fig. 2). The resultant shift in RA of only 3 -fold was insufficient to distinguish robustly between D1-like and D5-like activity, and the results with the chimeras were ambiguous.

Evidence That Mutation of Arginine-130 to Glutamine in IC2 Is Responsible for the Human/Rat Species Difference in Potency of DETQ. To confirm that arginine130 was responsible for the human/rat species difference, we mutated this residue to glutamine (the amino acid present in rat) and also created the reverse mutation $(\mathrm{Q} 129 \mathrm{R}$ in the rat sequence). The R130Q mutation shifted the human receptor to a rat-like potency and the $\mathrm{Q} 129 \mathrm{R}$ mutation of the rat $\mathrm{D} 1$ receptor reversed this shift, confirming that Arg $130^{\mathrm{IC} 2.3}$ is responsible for the human/rat species difference (Fig. 3). Inspection of published D1 sequences in the UniProt database (http://www.uniprot.org) shows that arginine is ancestral and the mutation to glutamine occurred in the crown of the rodent line, since the rat, mouse, and guinea pig show the glutamine mutation, whereas the rabbit (in Lagomorpha, a sister order to Rodentia) retains arginine, as do distant species such as Xenopus and Drosophila.

CID 2886111 had 2.4-fold higher potency at the rat D1 receptor compared with human D1 and was unaffected by the R130Q mutation. The divergent behavior of CID 2886111 compared with DETQ hints that their binding sites may be different (see below).

Insertion of the D1 IC2 Region into the $\beta 2$-Receptor Confers Sensitivity to DETQ. The $\beta 2$-adrenergic receptor, although closely related to the $\mathrm{D} 1$ receptor, does not respond to DETQ (Svensson et al., 2017). To find out whether the IC2 region is responsible for the PAM activity of DETQ, we replaced this region of the $\beta 2$ receptor with the 


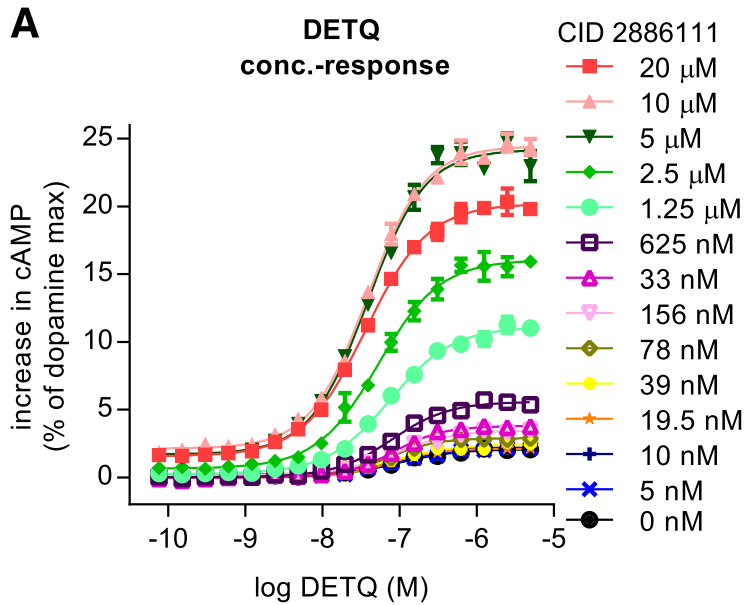

C

Effect of CID 2886111 on max and EC50 for DETQ

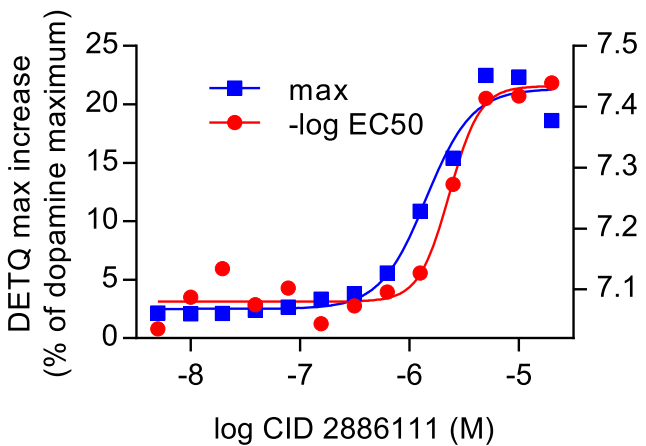

B

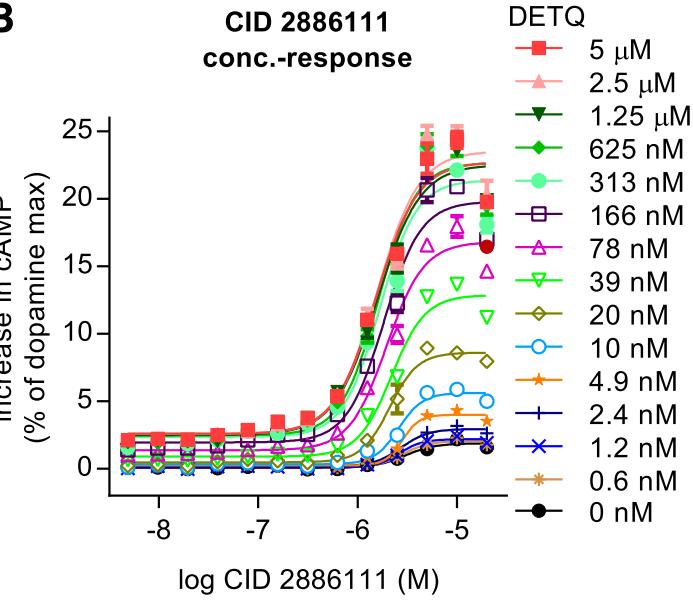

D

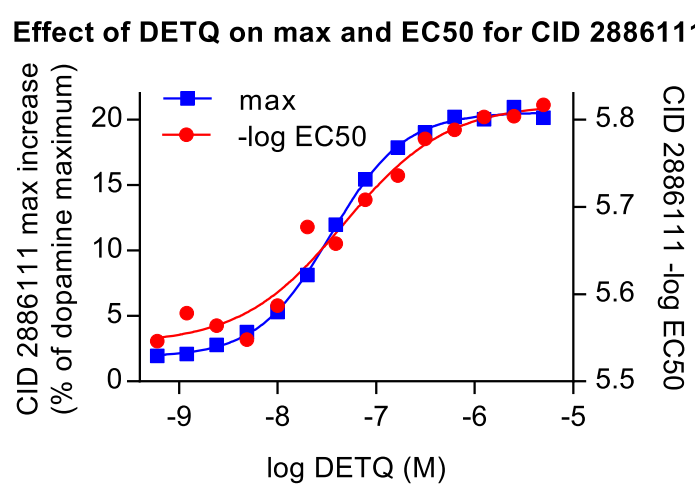

Fig. 5. Interaction between DETQ and CID 2886111 in the absence of dopamine. (A) CRCs for DETQ in the presence of different concentrations of CID 2886111.

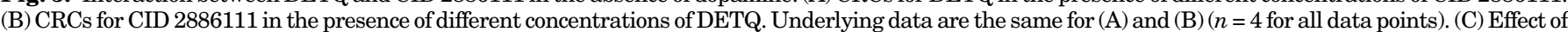

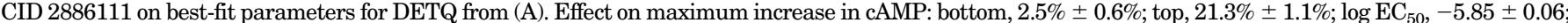

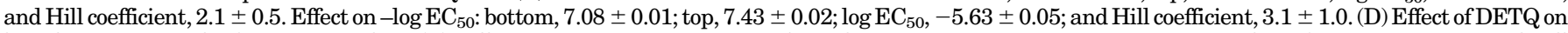

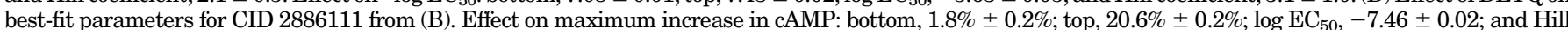

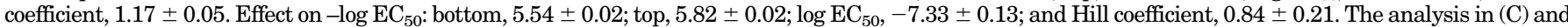

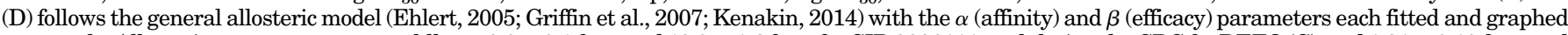

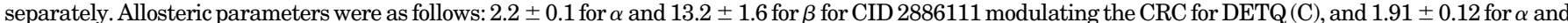

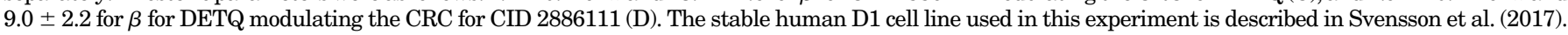

corresponding region from the D1 receptor. The residues that were replaced, consisting of IC2 and adjacent parts of TM3 and TM4 $\left(\mathrm{V}^{3.45}\right.$ through $\left.\mathrm{I}^{4.46}\right)$, were chosen based on a homology model described below. DETQ robustly potentiated the response to norepinephrine in this construct, with a potency about 5-fold lower than at the human D1 receptor (Fig. 4). This result indicates that the IC2 region is sufficient to confer PAM activity of DETQ, although the 5-fold loss of potency suggests an auxiliary role for residues outside this region.

CID 2886111 blocked the activation of the $\beta 2$ receptor by norepinephrine (Fig. 4). This result suggests that CID 2886111 may be a NAM at the $\beta 2$ receptor, a possibility that should be investigated in more detail. Replacing the $\beta 2$ IC2 region with the corresponding D1 sequence did not restore PAM activity, indicating that CID 2886111 binds to a different site than DETQ.

Evidence from Interaction Studies That DETQ and CID 2886111 Bind to Different Sites. If DETQ and CID 2886111 bind to different sites but stabilize the same receptor conformation, the theory of linked equilibria (Monod et al., 1965; Koshland et al., 1966; Canals et al., 2012; Changeux and Christopoulos, 2017) predicts that they will act cooperatively (supra-additively) to activate the receptor. In the absence of dopamine, each PAM by itself increased cAMP to only about $2 \%$ of the dopamine maximum, but in combination (without

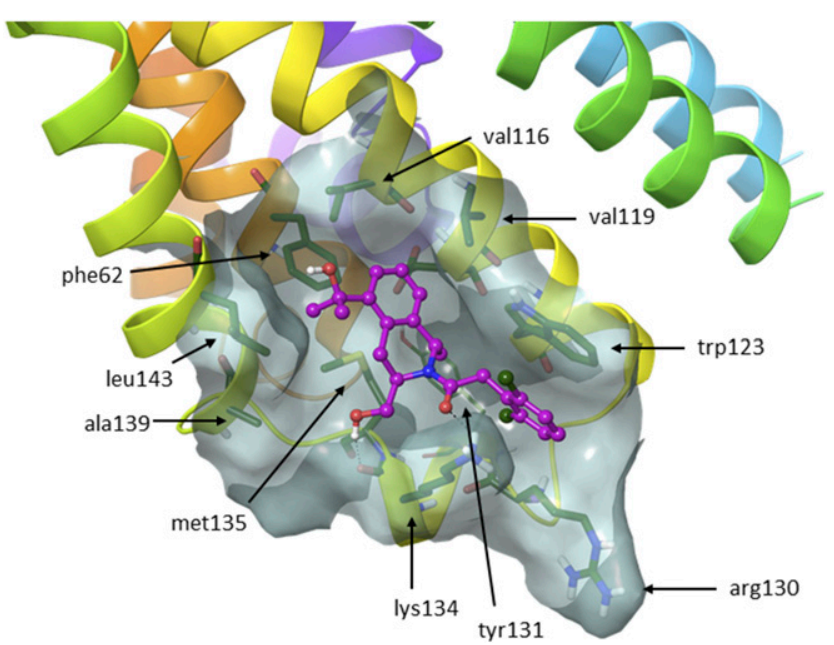

Fig. 6. Homology model of the IC2 region of the D1 receptor with DETQ bound. TM2, TM3, and TM4 are orange, yellow, and chartreuse, respectively. 
A

DETQ

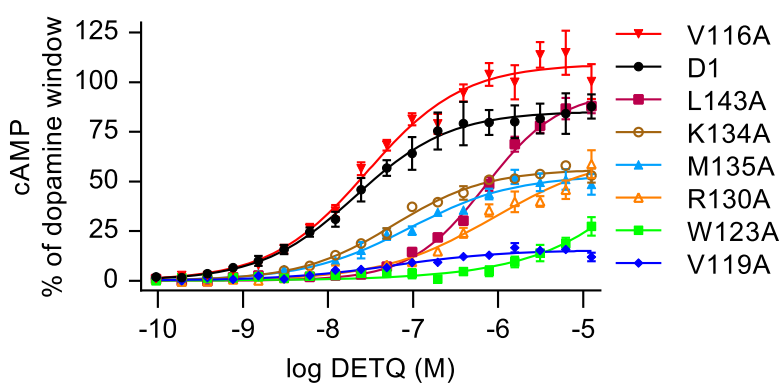

C

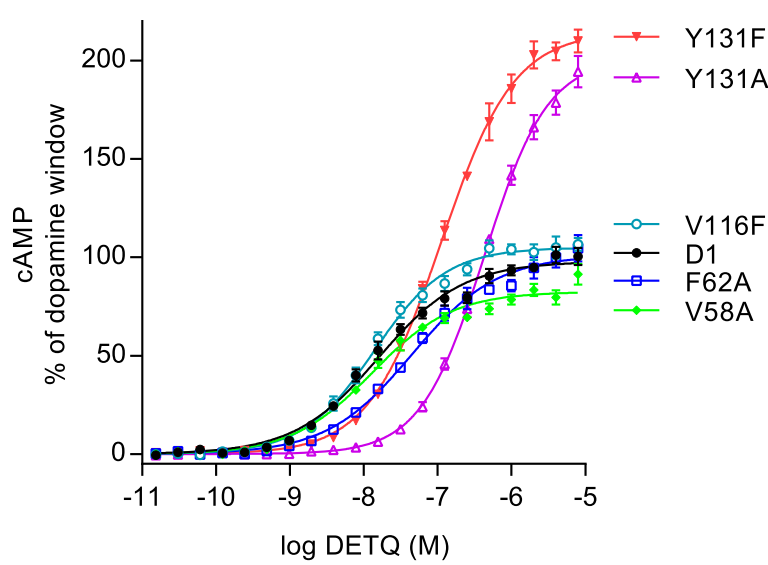

Binding Site Model

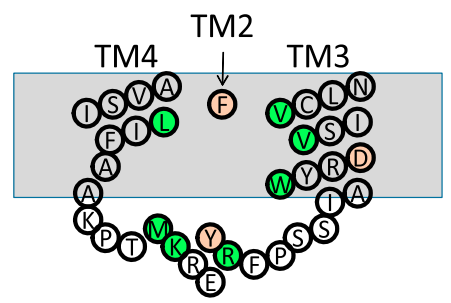

IC2

green: sidechain projects into binding site

pink: on floor of binding site
B

CID 2886111

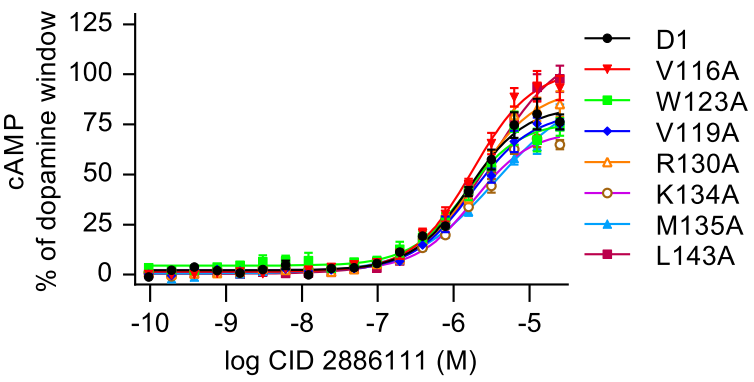

CID 2886111

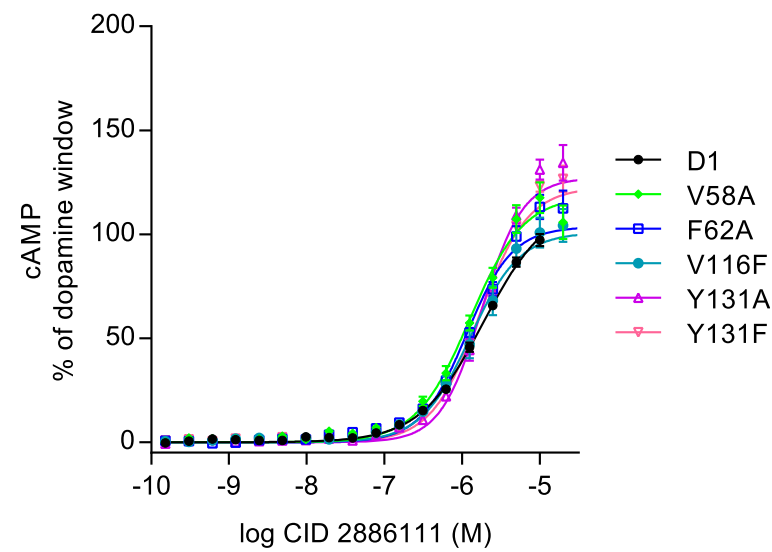

DETQ Potency

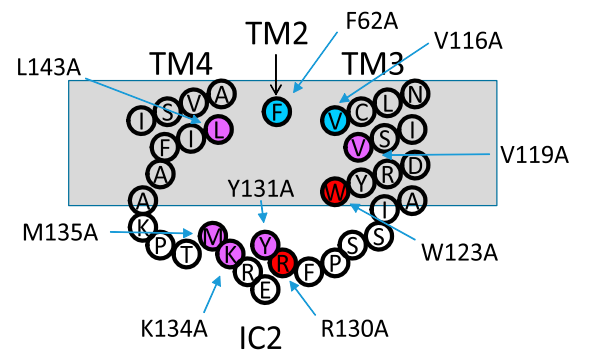

blue: $30-300 \%$ of wild-type

violet: $3-30 \%$ of wild-type

Fig. 7. Alanine scan of residues that had potential binding interactions with DETQ in the homology model. The V116F and Y131F mutants are included for comparison. (A-D) CRCs of DETQ and CID 2886111 for accumulation of cAMP were carried out in the presence of an $\mathrm{EC}_{20}$ concentration of dopamine. Transient transfections were used in (A) and (B), and stable cell lines were used in (C) and (D). Values are best-fit parameters \pm S.E. $(n=6)$ from nonlinear least-squares curve-fitting to a four-parameter model with the bottom of the dopamine window fixed to zero. "Top" is the fitted top as a percentage of the fitted dopamine top in the same mutant. Additional details including Hill coefficients and $\mathrm{EC}_{20}$ dopamine concentrations are provided in Supplemental Table 2. The curve for DETQ in W123A (A) had a Hill coefficient fixed to 1. For the rationale, see the section on fitting of incomplete curves in the Materials and Methods.

dopamine) they increased cAMP to about $23 \%$ of the dopamine maximum (Fig. 5), a much higher response than predicted by additivity. Each PAM also shifted the $\mathrm{EC}_{50}$ of the other about 2 -fold to the left. In contrast to the synergy between DETQ and CID 2886111, combinations of two PAMs from the acyltetrahydroisoquinoline series (Beadle et al., 2014) did not produce a response higher than the maximum for either compound tested separately (unpublished observation). The mutual synergy of dopamine, DETQ, and CID 2886111 implies that they bind to three separate sites yet drive the same receptor conformation. A recent abstract provides similar evidence for two separate D1 PAM sites (Luderman et al., 2018).

Homology Model of the Intracellular Binding Site for DETQ. To explore the binding site for DETQ, a homology model was constructed based on $3 \mathrm{p} 0 \mathrm{~g}$, an agonist-state crystal structure of the human $\beta 2$ receptor in complex with a nano-antibody 


\begin{tabular}{|c|c|c|c|c|c|c|c|c|c|c|c|c|c|c|c|c|c|c|c|c|}
\hline \multirow{3}{*}{$\begin{array}{l}\text { mutant } \\
\text { D1 (panels A \& B) }\end{array}$} & \multicolumn{10}{|c|}{ DETQ } & \multicolumn{10}{|c|}{ CID 2886111} \\
\hline & \multicolumn{3}{|c|}{$\mathrm{EC50}(\mathrm{nM})$} & \multicolumn{3}{|c|}{$\begin{array}{c}\text { top (\% of DA } \\
\text { window) }\end{array}$} & \multicolumn{3}{|c|}{$\begin{array}{c}\text { relative } \\
\text { activity (X } \\
1000)\end{array}$} & \multirow{2}{*}{\begin{tabular}{|c|} 
RA as \% of \\
wild-type \\
D1 \\
100
\end{tabular}} & \multicolumn{3}{|c|}{ EC50 (nM) } & \multicolumn{3}{|c|}{$\begin{array}{c}\text { top (\% of } \\
\text { DA } \\
\text { window) }\end{array}$} & \multicolumn{3}{|c|}{$\begin{array}{c}\text { relative } \\
\text { activity (X } \\
1000)\end{array}$} & $\begin{array}{c}\text { RA as } \% \text { o } \\
\text { wild-type } \\
\text { D1 }\end{array}$ \\
\hline & 21 & \pm & 1 & 85 & \pm & 1 & 4000 & \pm & 300 & & $1530=$ & & 220 & 86 & $\pm<$ & 4 & 56 & \pm & 8 & 100 \\
\hline D1 (panels C \& D) & 15.8 & \pm & 1.4 & 98 & \pm & 2 & 6200 & \pm & 600 & 100 & 1870 & \pm & 150 & 115 & $\pm<$ & 4 & 61 & \pm & 5 & 100 \\
\hline $\mathrm{V} 58^{2.38} \mathrm{~A}$ & 13.0 & \pm & 1.3 & 83 & \pm & 1 & 6400 & \pm & 600 & 103 & $1260=$ & \pm & 120 & 119 & \pm & 4 & 94 & \pm & 9 & 153 \\
\hline $\mathrm{F} 62^{2.42} \mathrm{~A}$ & 45 & \pm & 5 & 101 & \pm & 2 & 2300 & \pm & 300 & 37 & $1140=$ & \pm & 100 & 104 & \pm & 3 & 91 & \pm & 8 & 148 \\
\hline $\mathrm{V} 116^{3.45} \mathrm{~A}$ & 28 & \pm & 4 & 109 & \pm & 3 & 3800 & \pm & 600 & 95 & 1760 & \pm & 200 & 104 & \pm & 4 & 59 & \pm & 7 & 105 \\
\hline $\mathrm{V} 116^{3.45} \mathrm{~F}$ & 13.9 & \pm & 1.1 & 105 & \pm & 1 & 7600 & \pm & 600 & 122 & 1270 & \pm & 140 & 101 & \pm 3 & 3 & 79 & \pm & 9 & 129 \\
\hline $\mathrm{V} 119^{3.48} \mathrm{~A}$ & 59 & \pm & 23 & 15.5 & \pm & 1.1 & 260 & \pm & 100 & 6.5 & 1760 & \pm & 190 & 83 & \pm 3 & 3 & 47 & \pm & 5 & 84 \\
\hline $\mathrm{W} 123^{3.52} \mathrm{~A}$ & 4900 & \pm & 1700 & 37 & \pm & 6 & 7.5 & \pm & 2.9 & 0.18 & 1420 & \pm & 370 & 82 & $\pm \epsilon$ & 6 & 57 & \pm & 16 & 103 \\
\hline $\mathrm{R} 130^{\mathrm{IC} 2.3} \mathrm{~A}$ & 890 & \pm & 350 & 64 & \pm & 6 & 71 & \pm & 29 & 1.76 & $1930=$ & \pm & 240 & 94 & \pm 4 & 4 & 49 & \pm & 6 & 87 \\
\hline $\mathrm{Y} 131^{\mathrm{IC} 2.4} \mathrm{~A}$ & 430 & \pm & 30 & 200 & \pm & 4 & 470 & \pm & 30 & 7.6 & 1790 & \pm & 110 & 127 & \pm 3 & 3 & 71 & \pm & 5 & 116 \\
\hline $\mathrm{Y} 131^{\mathrm{IC} 2.4} \mathrm{~F}$ & 111 & \pm & 7 & 220 & \pm & 3 & 1940 & \pm & 120 & 31 & 1690 & \pm & 90 & 123 & \pm 2 & 2 & 73 & \pm & 4 & 118 \\
\hline $\mathrm{K} 1344^{\mathrm{IC} 2.7} \mathrm{~A}$ & 59 & \pm & 6 & 56 & \pm & 1 & 950 & \pm & 100 & 24 & $1830=$ & \pm & 300 & 74 & \pm & 4 & 41 & \pm & 7 & 73 \\
\hline $\mathrm{M} 135^{\mathrm{I} 22.8} \mathrm{~A}$ & 91 & \pm & 18 & 53 & \pm & 2 & 580 & \pm & 120 & 14.4 & 3760 & \pm & 790 & 95 & $\pm \epsilon$ & 6 & 25 & \pm & 6 & 45 \\
\hline $\mathrm{L} 143^{4.45} \mathrm{~A}$ & 700 & \pm & 60 & 95 & \pm & 3 & 135 & \pm & 13 & 3.3 & 3100 & \pm & 420 & 115 & \pm 5 & 5 & 37 & \pm & 5 & 66 \\
\hline
\end{tabular}

Fig. 7. Continued.

(Rasmussen et al., 2011a). Confidence in the model was supported by the high homology between the D1 and $\beta 2$ receptors (14 of 28 amino acids identical in the IC2 region, defined as $\mathrm{V} 116^{3.45}$ through $\mathrm{L} 143^{4.45}$ ) and the lack of any insertions or deletions in the IC2 region. In the $\beta 2$ receptor and the homology model, this region consists of a twisted loop, with TM3 passing under TM4 and IC2 connecting the two in a retrograde direction compared with the other two IC loops (Fig. 6). The middle of the IC2 bend is organized into a short $\alpha$-helix. Notably, the inside surface of the bend forms a cleft large enough to accommodate a small-molecule ligand such as DETQ. Unlike the outer surface of the IC2 bend (Rasmussen et al., 2011b), the inner surface has few direct interactions with $\mathrm{G}_{\mathrm{s}}$ or neighboring TM segments and is relatively less conserved (Ballesteros and Weinstein, 1995), potentially explaining the high specificity of DETQ for the D1 receptor over closely related receptors. Residues that line the inside of the loop (and therefore may interact with a small-molecule PAM ligand) are labeled in Fig. 6.

DETQ was able to dock in several orientations, and the pose shown was selected based on consistency with observed structure-activity relationships (Beadle et al., 2014). The nearly flat tetrahydroisoquinoline ring system lies across the cleft, with the benzene ring of the tetrahydroisoquinoline at the "upper" (intramembrane) end of the cleft. The dichlorophenyl moiety is oriented nearly perpendicular to the tetrahydroisoquinoline ring and is sandwiched between the side chains of $\mathrm{W} 123^{3.52}$ and $\mathrm{R} 130^{\mathrm{IC} 2.3}$. The amide group forms a bridge between the two ring systems, forming a potential hydrogen bond with the amino group of K134 ${ }^{\mathrm{IC} 2.4}$. The 3-position hydroxyl forms a potential hydrogen bond with the carbonyl of K134.

The "right-hand" or TM3 side of the cleft is lined by V116 $6^{3.45}$, $\mathrm{V} 119^{3.48}$, and $\mathrm{W} 123^{3.52}$, the latter two residues bracketing the canonical DRY sequence that is known to be involved in agonist coupling (Rasmussen et al., 2011a,b). R130 ${ }^{\mathrm{IC} 2.3}$ and $\mathrm{K} 134^{\mathrm{IC} 2.4}$ line the inner surface of the $\alpha$-helical portion of IC2, whereas
A139 $9^{4.41}$ and $\mathrm{L} 143^{4.45}$ are located on the left side of the cleft, although A139 is recessed and does not interact with DETQ in the model. Finally, side chains of $\mathrm{Y} 131^{\mathrm{IC} 2.4}$ and $\mathrm{M} 135^{\mathrm{IC} 2.8}$ are located on the floor of the cleft along with the benzene ring of $\mathrm{F} 62^{2,42}$, which intercalates into the IC2 loop from TM2.

Alanine Scan of the Binding Site. The amino acids modeled as forming potential contacts with DETQ were each mutated to alanine. CID 2886111, which binds to a different site, was used as a control to monitor possible effects of changes in receptor expression or coupling in the mutants that might masquerade as disruption of binding contacts with DETQ.

The W123 $3^{3.52} \mathrm{~A}$ mutation caused the largest effect, roughly a 500-fold loss of potency (Fig. 7). In agreement with its importance, the large planar ring system is modeled as extending parallel to the cleft, forming a large portion of the surface area of the TM3 side of the cleft. The electron-deficient dichlorophenyl group forms a $\pi$-stacking interaction with the electron-rich tryptophan ring in the homology model.

Interestingly, the $\mathrm{V} 119^{3.48} \mathrm{~A}$ replacement lowered efficacy of DETQ to about $15 \%$ without affecting the $\mathrm{EC}_{50}$. Mutation of R130, K134, M135, and L143 to alanine also had substantial effects on potency, ranging from about 4-fold for K134 to about 60 -fold for R130. The large effects of these residues confirm the general topology of the IC2 region in the homology model. The relatively weak (4-fold) effect of the K134A mutation suggests that the H-bond between the K134 amine and the bridge carbonyl of DETQ in the homology model may not exist or may be energetically unimportant.

In the activated state of the $\beta 2$ receptor, $\mathrm{Y} 131^{\mathrm{IC} 2.4}$ forms a hydrogen bond with the aspartate in the DRY sequence (Rasmussen et al., 2011b). To separate the role of this residue in coupling from its potential role in forming a binding interaction with DETQ, we created two mutants. In Y131F, tyrosine is replaced with phenylalanine, which lacks hydrogenbonding ability but retains the same aromatic ring, whereas in Y131A the alanine lacks both hydrogen-bonding and 
A

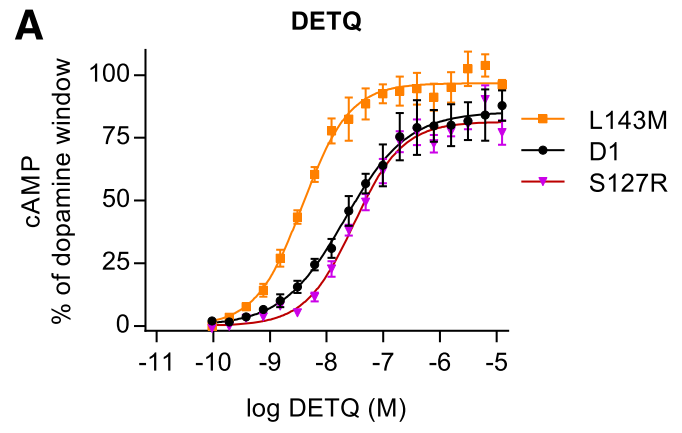

C

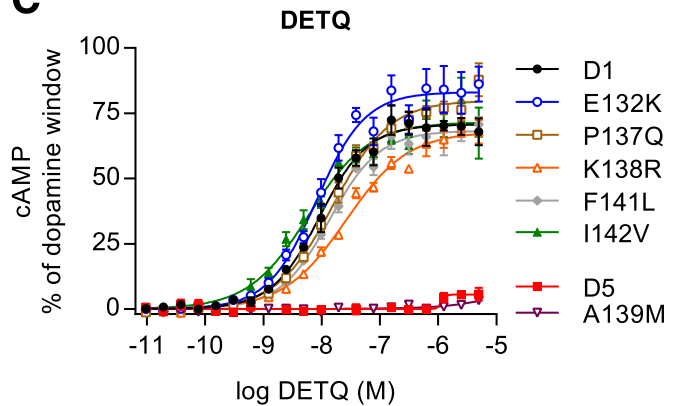

$\mathbf{E}$

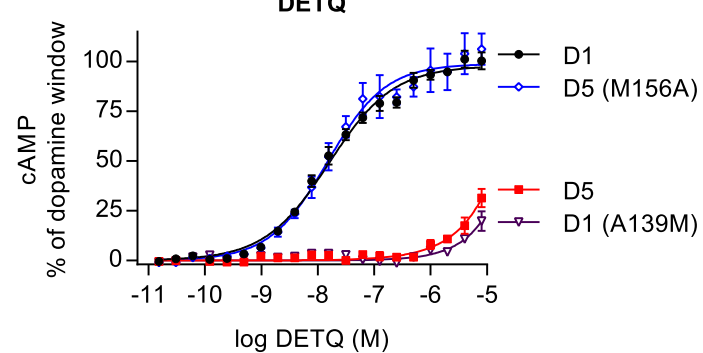

B

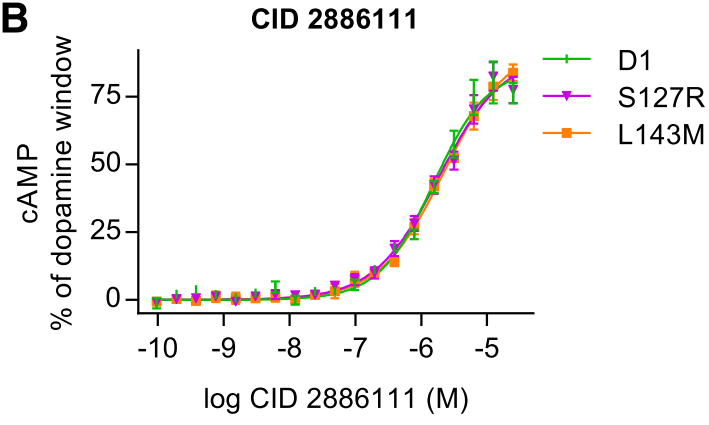

D

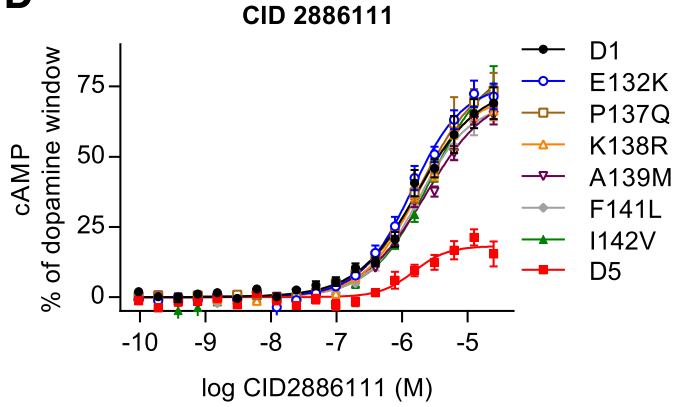

$\mathbf{F}$

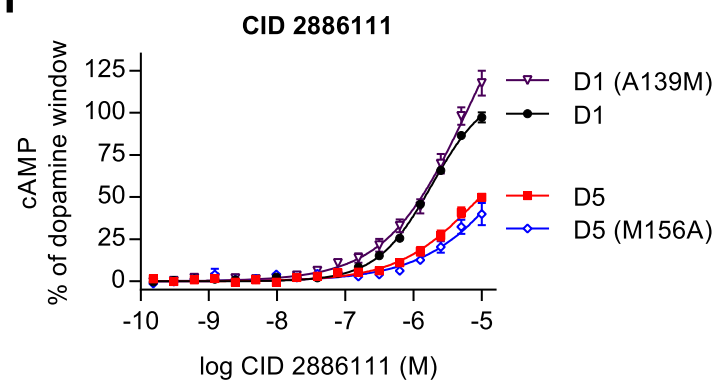

DETQ Potency

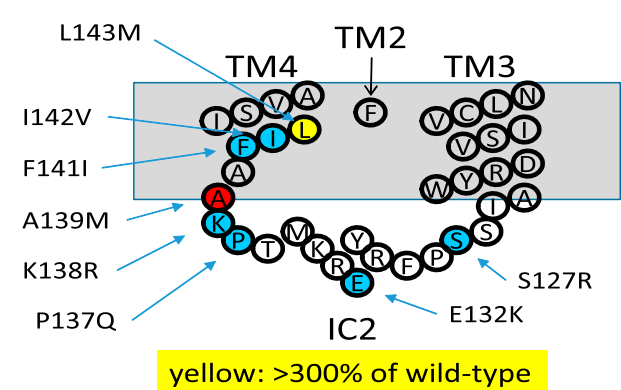

blue: $30-300 \%$ of wild-type

red: $<3 \%$ of wild-type

Fig. 8. Replacement of D1 residues with their D5 counterparts. (A-F) CRCs of DETQ and CID 2886111 for accumulation of cAMP were carried out in the presence of an $\mathrm{EC}_{20}$ concentration of dopamine. Transient transfections were used in (A) and (B), and stable cell lines were used in (C) through (F). Values are best-fit parameters \pm S.E. $(n=6)$ from nonlinear least-squares curve-fitting to a four-parameter model with the bottom of the dopamine window fixed to zero. Additional details including Hill coefficients and $\mathrm{EC}_{20}$ dopamine concentrations are provided in Supplemental Table 2. The curves for CID 2886111 in wild-type D5 and D5 M156A (F) had a Hill coefficient fixed to 1. For DETQ in D5 and A139M (E), curve-fitting parameters could only be obtained by fixing the Hill coefficient to 1 and the top to $100 \%$. For the rationale, see the section on fitting of incomplete curves in the Materials and Methods.

aromaticity. As expected, the functional affinity of dopamine was considerably weaker (about 50 -fold) in both mutants (Supplemental Fig. 1; Supplemental Tables 3 and 4). Additionally, in both mutants, the combination of DETQ and dopamine was able to elicit a much larger maximum response than dopamine alone, indicating that dopamine is incapable of fully activating the receptor by itself in these mutants.
In agreement with this interpretation, the maximum response to dopamine in these two mutants was considerably less than that seen in wild-type D1 (Supplemental Fig. 1; Supplemental Tables 3 and 4). When RA was calculated relative to the dopamine maximum in the same mutant, the Y131A mutant lowered RA by about 13-fold, whereas the Y131F mutant reduced RA by only 3 -fold. This result suggests that the alanine 


\begin{tabular}{|c|c|c|c|c|c|c|c|c|c|c|c|c|c|c|c|c|c|c|c|c|}
\hline \multirow{3}{*}{$\begin{array}{l}\text { mutant } \\
\text { D1 (panels A \& B) }\end{array}$} & \multicolumn{10}{|c|}{ DETQ } & \multicolumn{10}{|c|}{ CID 2886111} \\
\hline & \multicolumn{3}{|c|}{ EC50 (nM) } & \multicolumn{3}{|c|}{$\begin{array}{l}\text { top (\% of DA } \\
\text { window) }\end{array}$} & \multicolumn{3}{|c|}{$\begin{array}{l}\text { relative activity } \\
\qquad(X 1000)\end{array}$} & $\begin{array}{c}\text { RA as \% of } \\
\text { wild-type } \\
\text { D1 }\end{array}$ & \multicolumn{3}{|c|}{ EC50 (nM) } & \multicolumn{3}{|c|}{$\begin{array}{c}\text { top (\% of } \\
\text { DA } \\
\text { window) }\end{array}$} & \multicolumn{3}{|c|}{$\begin{array}{l}\text { relative } \\
\text { activity (X } \\
1000)\end{array}$} & $\begin{array}{c}\text { RA as \% of } \\
\text { wild-type } \\
\text { D1 }\end{array}$ \\
\hline & 21 & \pm & 1 & 85 & \pm 1 & 1 & $4000 \pm$ & \pm & 300 & 100 & $1530 \pm$ & & 220 & 86 & \pm & 4 & $56 \pm$ & \pm & 8 & 100 \\
\hline D1 (panels C \& D) & 9.2 & \pm & 1.0 & 71 & \pm & 2 & $7700 \pm$ & \pm & 900 & 100 & $1820 \pm$ & & 480 & 76 & \pm & 7 & $42 \pm$ & \pm & 12 & 100 \\
\hline D1 (panels E \& F)) & 15.8 & \pm & 1.4 & 98 & \pm & 2 & $6200 \pm$ & \pm & 600 & 100 & $1870 \pm$ & \pm & 150 & 115 & \pm & 4 & $61 \pm$ & \pm & 5 & 100 \\
\hline D5 (panels C \& D) & $>5000$ & & & $<10$ & & & $<4$ & \pm & & $<0.1$ & $2300 \pm$ & \pm & 900 & 23 & \pm & 4 & $9.7 \pm$ & \pm 4 & 4.2 & 23 \\
\hline D5 (panels E \& F)) & 17400 & \pm & 1100 & $=100$ & & & $5.8 \pm$ & \pm & 0.4 & 0.09 & $3200 \pm$ & \pm & 400 & 66 & \pm & 4 & $20 \pm$ & \pm & 3 & 33 \\
\hline $\mathrm{S} 127^{3.58} \mathrm{R}$ & 30 & \pm & 3 & 81 & \pm & 2 & $2700=$ & \pm & 300 & 66 & $1840 \pm$ & \pm & 290 & 90 & \pm & 4 & $49 \pm$ & \pm & 8 & 88 \\
\hline $\mathrm{E} 132^{\mathrm{IC} 2.5} \mathrm{~K}$ & 8.1 & \pm & 1.0 & 83 & \pm & 2 & $10200 \pm$ & \pm & 1300 & 133 & $1570 \pm$ & \pm & 250 & 79 & \pm & 5 & $51 \pm$ & \pm & 9 & 120 \\
\hline $\mathrm{P} 137^{4.39} \mathrm{Q}$ & 15.9 & \pm & 1.5 & 80 & \pm & 1 & $5000=$ & \pm & 500 & 66 & $2100 \pm$ & \pm & 600 & 83 & \pm & 8 & $39 \pm$ & \pm & 11 & 93 \\
\hline $\mathrm{K} 138^{4.40} \mathrm{R}$ & 26 & \pm & 3 & 68 & \pm & 1 & $2600=$ & \pm & 300 & 34 & $1930 \pm$ & \pm & 270 & 77 & \pm & 4 & $40 \pm$ & \pm & 6 & 95 \\
\hline $\mathrm{A} 139^{4.41} \mathrm{M}$ (panels C \& D) & $>5000$ & & & $<10$ & & & $<4$ & \pm & & $<0.1$ & $2800 \pm$ & \pm & 500 & 79 & \pm & 5 & $28 \pm$ & \pm & 6 & 67 \\
\hline $\mathrm{A} 139^{4.41} \mathrm{M}$ (panels E \& F) & 33000 & \pm & 3000 & $=100$ & & & $3.1 \pm$ & \pm & 0.3 & 0.05 & $1200 \pm$ & \pm & 140 & 106 & \pm & 4 & $88 \pm$ & \pm & 11 & 143 \\
\hline D5 $M 156^{4.41} A$ & 14.8 & \pm & 2.5 & 99 & \pm & 3 & $6700=$ & \pm & 1100 & 108 & $4300 \pm$ & \pm 1 & 1200 & 57 & \pm & 7 & $13.5 \pm$ & \pm 4 & 4.1 & 22 \\
\hline $\mathrm{F} 141^{4.43} \mathrm{I}$ & 13.6 & \pm & 1.4 & 68 & \pm & 1 & $5000 \pm$ & \pm & 500 & 65 & $1670 \pm$ & \pm & 230 & 68 & \pm & 4 & $41 \pm$ & \pm & 6 & 97 \\
\hline $1142^{4.44} \mathrm{~V}$ & 5.9 & \pm & 1.0 & 72 & \pm & 2 & $12100=$ & & 2000 & 157 & $2500 \pm$ & \pm & 500 & 80 & \pm & 7 & $32 \pm$ & \pm & 7 & 77 \\
\hline $\mathrm{L} 143^{4.45} \mathrm{M}$ & 3.8 & \pm & 0.3 & 97 & \pm & 1 & $26000=$ & \pm & 2000 & 631 & $2200 \pm$ & \pm & 200 & 94 & \pm & 2 & $43 \pm$ & \pm & 4 & 76 \\
\hline
\end{tabular}

Fig. 8. Continued.

substitution disrupted a specific interaction between DETQ and its binding site, whereas the phenylalanine substitution disrupted general coupling of the D1 receptor but had a smaller effect on its specific binding interaction with DETQ. A similar pattern was seen with the $\mathrm{F} 62^{2.42} \mathrm{~A}$ mutation, in which the potency of dopamine was decreased about 15-fold (Supplemental Table 3), but the RA of DETQ was reduced only 3-fold (Fig. 7), indicating a strong effect on coupling or expression but only a modest effect on affinity of DETQ.

Of the residues modeled as potentially interacting with DETQ, V116 $6^{3.45}$ was the only one to lack any measurable effect when replaced with alanine (Fig. 7). This result constrains how far the DETQ molecule extends up the IC2 cleft.

The V $58^{2.38} \mathrm{~A}$ mutation was previously reported to lower the affinity of compound B by 220 -fold (Lewis et al., 2015). In our homology model, the side chain of this residue does not extend into the PAM binding site, but does underlie Met $135^{\mathrm{IC} 2.8}$, leaving open the possibility of an indirect influence on PAM binding. However, theV58A mutation had no effect on potency of DETQ, suggesting a difference in binding mode between DETQ and the more bulky compound B.

The potency of CID 2886111 was unaffected by any of the above mutations, confirming that the effects on potency of DETQ seen with the mutants reflect disruption of specific binding interactions with DETQ as opposed to secondary effects on other parameters such as receptor expression or coupling.

Role of Alanine-139 in the D1/D5 Species Difference in Affinity for DETQ. The alanine scan described above did not identify the residue responsible for the roughly 1000 -fold loss of affinity of DETQ at the D5 receptor. We therefore separately mutated each residue in the D1 IC2 region that differed from its D5 counterpart (Fig. 8).

Seven of the eight residues tested either had little effect on potency of DETQ or (in the case of $\mathrm{L} 143^{4.45} \mathrm{M}$ ) actually increased potency. However, the $\mathrm{A} 139^{4.41} \mathrm{M}$ mutation caused a striking $>1000$-fold loss of potency of DETQ. Interestingly, in the homology model, the side chain of alanine-139 is recessed and does not appear to interact with DETQ, but its small size leaves open a niche in the side of the binding cleft into which the 3-position hydroxymethyl of DETQ extends. The much larger methionine side chain present in the D5 receptor would cause severe steric interference with the 3-hydroxymethyl of DETQ in this binding pose. As expected, replacement of methionine with alanine in this position of the D5 receptor restored affinity for DETQ (Fig. 8).

None of the IC2 mutations had any notable effect on activity of CID 2886111.

Amino Acids Involved in the D1/ß2 Difference in Affinity for DETQ. The origin of DETQ's inactivity at the $\beta 2$-adrenergic receptor was also of interest. The four residues that interacted with DETQ in the homology model and differed between the $\mathrm{D} 1$ and $\beta 2$ receptors were each separately mutated to their $\beta 2$ counterparts. (Alanine-139, the amino acid involved in the D1/D5 difference, is altered to lysine in the $\beta 2$ receptor; the effect of this change was not investigated.) Each of the substitutions caused a substantial loss of potency, ranging from 7- to 80-fold (Fig. 9). The 80-fold loss of potency with the W123F mutation was less severe than the 500-fold loss with the W123A mutation (Fig. 7), and the same was true for R130K compared with R130A (7-fold and 60 -fold, respectively). The other two mutants (K134L and M135L) both showed roughly the same magnitude of effect as the corresponding alanine substitutions. None of the mutations affected the potency of CID 2886111.

\section{Discussion}

This report describes two sites for allosteric modulation of the dopamine D1 receptor. Results with D1 receptor chimeras and mutants show that the D1 PAM DETQ occupies a cleft in IC2 as previously described for compound B (Lewis et al., 2015). In addition, we show that another D1 PAM, CID 2886111, occupies a separate site (exact location not yet identified) that interacts synergistically with the DETQ site. These results imply a rich structural landscape for allosteric modulation of the D1 receptor and other GPCRs. 
The IC2 region to which DETQ binds is critically involved in the structural changes that accompany the transition between the inactive and active conformations of class A GPCRs. Upon receptor activation, Asp ${ }^{3.49}$ of the conserved DRY sequence at the cytoplasmic end of TM3 breaks a hydrogen bond with $\mathrm{Arg}^{3.50}$ and forms a new hydrogen bond with $\mathrm{Tyr}^{\mathrm{IC} 2.4}$, freeing $\operatorname{Arg}^{3.50}$ to interact with Tyr391 of the $\alpha$-subunit of $\mathrm{G}_{\mathrm{S}}$ (Rasmussen et al., 2011b). In this study, Val119 $9^{3.48}$ and Trp $123^{3.52}$, which flank the DRY sequence in the D1 receptor, were found to be critical for DETQ potency. Interestingly, the V119A mutation reduced the efficacy of DETQ to about $15 \%$, suggesting that DETQ may exert a steric push on Val119, which in turn may rotate the DRY sequence and facilitate a remodeling of its hydrogen-bond network into the activated-state pattern. In a similar light, $\mathrm{Ph} \mathrm{e}^{\mathrm{IC} 2.2}$, immediately adjacent to $\mathrm{R} 130^{\mathrm{IC} 2.3}$, binds to a hydrophobic pocket in the $\alpha$-subunit of $\mathrm{G}_{\mathrm{S}}$ and has a critical role in G-protein coupling (Moro et al., 1993; Rasmussen et al., 2011b). These results taken together provide hints with respect to how DETQ enhances coupling of the D1 receptor to $G_{s}$.

The intracellular location of the IC2 site may have implications for the pharmacology of DETQ and its congeners. The acyl-tetrahydroisoquinolines (Beadle et al., 2014) are quite hydrophobic and generally should cross cell membranes easily, but the intracellular location of the site should be borne in mind when interpreting structure-activity relationships based on whole-cell assays. The lack of probe dependence seen with DETQ (Svensson et al., 2017) may relate to the relatively large distance of the IC2 site from the orthosteric
DETQ

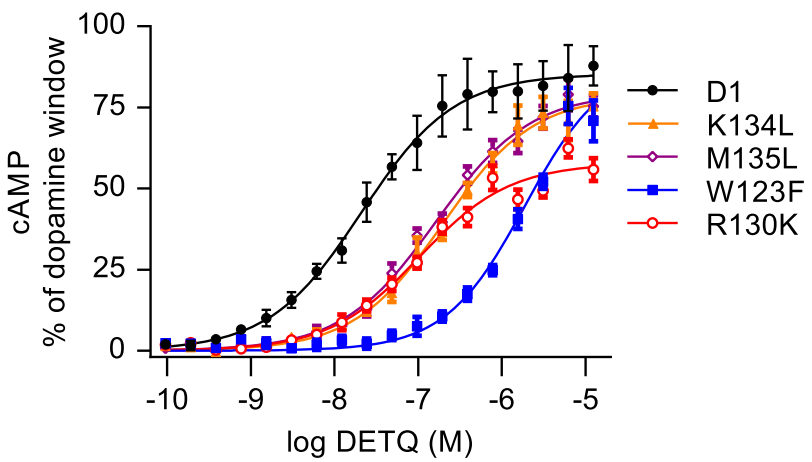

CID 2886111

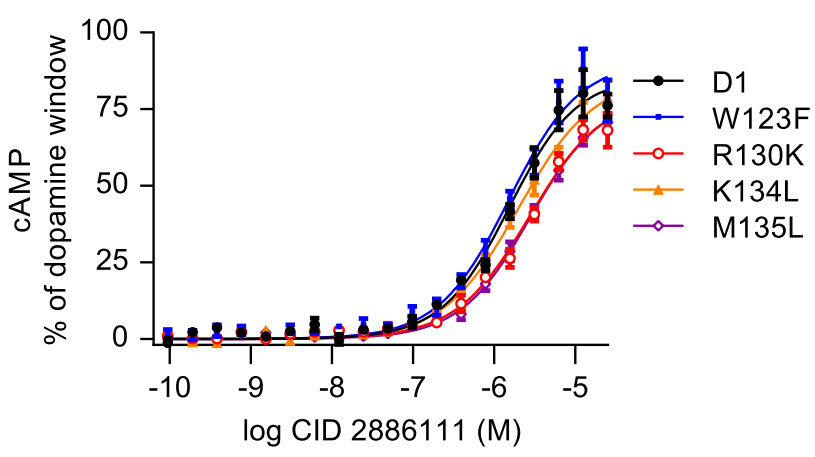

DETQ Potency

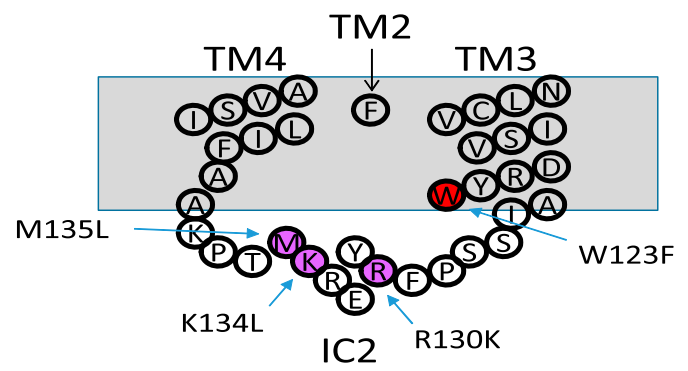

blue: $30-300 \%$ of wild-type

violet: $3-30 \%$ of wild-type

red: $<3 \%$ of wild-type

\begin{tabular}{|c|c|c|c|c|c|c|c|c|c|c|c|c|c|c|c|c|c|c|c|c|}
\hline \multirow{3}{*}{$\begin{array}{l}\text { mutant } \\
\text { D1 }\end{array}$} & \multicolumn{10}{|c|}{ DETQ } & \multicolumn{10}{|c|}{ CID 2886111} \\
\hline & \multicolumn{3}{|c|}{ EC50 (nM) } & \multicolumn{3}{|c|}{$\begin{array}{c}\text { top (\% of } \\
\text { DA } \\
\text { window) }\end{array}$} & \multicolumn{3}{|c|}{$\begin{array}{c}\text { relative } \\
\text { activity ( } \mathrm{X} \\
1000)\end{array}$} & \multirow{2}{*}{$\begin{array}{r}\text { RA as \% } \\
\text { of wild- } \\
\text { type D1 } \\
100\end{array}$} & \multicolumn{3}{|c|}{ EC50 (nM) } & \multicolumn{3}{|c|}{$\begin{array}{c}\text { top (\% of } \\
\text { DA } \\
\text { window) }\end{array}$} & \multicolumn{3}{|c|}{$\begin{array}{c}\text { relative } \\
\text { activity (X } \\
1000)\end{array}$} & \multirow{2}{*}{$\begin{array}{r}\text { RA as \% } \\
\text { of wild- } \\
\text { type D1 } \\
100\end{array}$} \\
\hline & 21 & \pm & 1 & 85 & \pm & 1 & 4000 & \pm & 300 & & 1530 & \pm & 220 & 86 & \pm & 4 & 56 & \pm & 8 & \\
\hline $\mathrm{W} 123^{3.52} \mathrm{~F}$ & 1890 & \pm & 540 & 89 & \pm & 9 & 47 & \pm & 14 & 1.2 & 1520 & \pm & 270 & 91 & \pm & 5 & 60 & \pm & 11 & 107 \\
\hline $\mathrm{R} 130^{\mathrm{IC} 2.3} \mathrm{~K}$ & 104 & \pm & 20 & 58 & \pm & 2 & 560 & \pm & 110 & 13.8 & 2700 & \pm & 400 & 80 & \pm & 4 & 29 & \pm & 5 & 52 \\
\hline $\mathrm{K} 134^{\mathrm{IC} 2.7} \mathrm{~L}$ & 200 & \pm & 18 & 79 & \pm & 2 & 390 & \pm & 40 & 9.7 & 2000 & \pm & 200 & 85 & \pm & 3 & 43 & \pm & 5 & 76 \\
\hline$M 135^{I C 2.8} L$ & 163 & \pm & 17 & 80 & \pm & 2 & 490 & \pm & 50 & 12.0 & 2800 & \pm & 200 & 79 & \pm & 2 & 29 & \pm & 2 & 51 \\
\hline
\end{tabular}

Fig. 9. Replacement of D1 residues with their $\beta 2$ counterparts. CRCs of DETQ and CID 2886111 for accumulation of cAMP were carried out in the presence of an $\mathrm{EC}_{20}$ concentration of dopamine. All experiments were carried out using transient expression. Values are best-fit parameters $\pm \mathrm{S} . \mathrm{E}$. $(n=6$ ) from nonlinear least-squares curve-fitting to a four-parameter model with the bottom of the dopamine window fixed to zero. Additional details including Hill coefficients and $\mathrm{EC}_{20}$ dopamine concentrations are provided in Supplemental Table 2. 
site; in contrast, muscarinic PAMs and NAMs that bind to the vestibule can show strikingly different effects in modulating the affinity of different orthosteric ligands, both agonists and antagonists (Stockton et al., 1983; Valant et al., 2012). This may be related to the vestibule's position immediately adjacent to the orthosteric site, so that binding to the vestibule can cause local changes in the shape of the orthosteric site and vice versa (Kruse et al., 2013). In addition to the above, some vestibule binders block the entry and exit of orthosteric ligands, slowing kinetics and mandating that the orthosteric ligand bind before the allosteric ligand (Proska and Tucek, 1994). These characteristics would not necessarily pertain to allosteric modulators that bind to the IC2 site or other sites that are more remote from the orthosteric site. It is possible that IC2 binders could exert local effects on the adjacent $G$ protein, which would likely manifest as selectivity for the G-protein signaling pathway. DETQ has roughly equal potency for the $G_{s}$ and $\beta$-arrestin pathways (Svensson et al., 2017), a result that is more consistent with a global effect on receptor conformation, but future PAMs could conceivably achieve pathway-selective signaling by this mechanism.

An important question relates to the role of membrane lipids in the IC2-region binding site. Roughly half of the site is composed of the cytoplasmic ends of transmembrane helices TM3 and TM4. Virtually all of the amino acids in this area are hydrophobic, and this portion of the binding site is probably covered with lipid tail-groups when not occupied by a D1 PAM. Is there an energetic penalty for displacement of lipids by DETQ, or conversely, is there an energetic advantage for DETQ to insert itself under a blanket of lipids? Does any particular endogenous lipid (e.g., cholesterol) preferentially bind to this region? A full model of the binding site will need to include the influence of the membrane component.

The ability of the D1 IC2 region to retain responsiveness to DETQ when inserted into a $\beta 2 / \mathrm{D} 1$ chimera suggests several opportunities. Could such a construct be used to obtain a threedimensional structure of the DETQ binding site? Several useful stratagems for stabilizing the agonist state of the $\beta 2$ receptor are known (Rasmussen et al., 2011a,b). Would the $\beta 2 / \mathrm{D} 1$ chimera retain responsiveness to DETQ when expressed in a transgenic animal? For instance, such an approach could be used to validate a $\beta 2$ PAM strategy for treatment of asthma (Ahn et al., 2018) even though no $\beta 2$ PAMs with in vivo activity have yet been reported. Could the chimera approach be extended to more distant receptors such as adenosine A2a or melanocortin MC4R? The $\beta 2 / \mathrm{D} 1$ chimera showed a 5 -fold loss of potency for DETQ compared with wild-type D1, suggesting at least a mild degree of distortion or strain of the DETQ binding site in the chimera. Would a greater sequence mismatch result in more profound loss of activity, and if so, could stabilizing mutations elsewhere in the receptor be used to restore activity? Chimeric receptors can be a powerful tool (Gearing et al., 2003), but the range of applicability of this approach needs to be explored in more depth.

The D1 PAM CID 2886111 was not affected by any of the IC2 mutations, indicating that it binds to a site that is distinct from the DETQ binding site and that non-local influences such as changes in coupling or receptor expression do not account for the effects of the mutants on the potency of DETQ. In addition, the synergy between CID 2886111 and DETQ confirms that both stabilize the same activated receptor conformation. The overall allosteric boost $(\alpha \bullet \beta=\gamma)$ of DETQ toward CID
$2886111(1.9 \bullet 9.0=17$-fold $)$ was similar in magnitude to its boost toward dopamine $(21 \bullet 1.22=25$-fold) (Svensson et al., 2017), indicating that DETQ synergizes to a similar degree with both ligands. This observation confirms the prediction from receptor theory (Ehlert, 2005; Kenakin, 2017) that the overall allosteric boost will be the same regardless of whether the compound being potentiated is a partial agonist such as CID 2886111 (in which case the main effect is on efficacy) or a full agonist such as dopamine (in which case the main effect is on affinity).

The general location of the binding site for CID 2886111 could not be definitively established with the D1/D5 chimeras, since its D1 and D5 potency differed by only a factor of three. However, the relative potencies of CID 2886111 for the different chimeras (Fig. 2) tend to favor a site in the C-terminal half of the receptor. One candidate would be the glucagon-like peptide 1 receptor PAM site on the outward-facing parts of the cytoplasmic ends of TMs 5, 6, and 7 (Nolte et al., 2014; Bueno et al., 2016). Additional experiments to identify and characterize the binding site for CID 2886111 are warranted.

How can structural knowledge of allosteric modulator binding sites be used to accelerate drug discovery? In the case of the acyl-tetrahydroisoquinoline series, our original rat/human chimera studies led to the creation of a human D1 receptor knock-in mouse (Svensson et al., 2017), which in turn enabled the animal studies required for advancement of a D1 PAM into clinical trials (http://www.lilly.com/pipeline/). In addition, the D1/D5 chimeras should be useful for locating the binding sites for new D1 PAMs discovered from screening, and single mutants such as W123A and A139M can identify screening hits that are structurally unrelated to the acyl-tetrahydroisoquinolines but nevertheless bind to the same IC2 site. Finally, knowledge of the residues that are important for potency could potentially be used for target hopping to discover allosteric modulators of related receptors. For example, through understanding the residues of the $\beta 2$ receptor that account for the loss of affinity of DETQ (Fig. 9), it might be possible to remodel the acyltetrahydroisoquinolines into $\beta 2 \mathrm{PAMs}$ by introducing compensatory changes into the ligand structure.

In conclusion, this study identifies the IC2 region as the binding site for the D1 PAM DETQ and characterizes the residues that are important for affinity and efficacy. In addition, the results show that the D1 PAM CID 2886111 binds to a different site from DETQ, and that DETQ and CID 2886111 synergize in their effects on cAMP accumulation. These results should aid in the design of novel allosteric modulators of GPCRs.

\section{Acknowledgments}

We thank Mark Bures for helpful advice on construction and interpretation of the homology model, Doug Johnson for conformational modeling of the acyl-tetrahydroisoquinolines, Doug Schober for 3H-SCH23390 binding to D1 wild-type and mutant constructs, Francis Willard for suggesting the D1/ $\beta 2$ chimera experiment, Erik Hembre for suggesting the use of D1 PAM chimeras for target validation, and Kevin Burris for helpful feedback. We thank anonymous reviewer 1 for bringing up the issue of a possible local interaction between DETQ and $\mathrm{G}$ protein.

\section{Authorship Contributions}

Participated in research design: Wang, Heinz, Qian, Gadski, Little, Yang, Schaus, Svensson, Bruns.

Conducted experiments: Wang, Carter, Beavers, Bruns. 
Contributed new reagents or analytic tools: Qian, Beck, Hao, Schaus, Bruns.

Performed data analysis: Wang, Heinz, Qian, Gadski, Beavers, Bruns.

Wrote or contributed to the writing of the manuscript: Wang, Heinz, Yang, Schaus, Svensson, Bruns.

\section{References}

Ahn S, Pani B, Kahsai AW, Olsen EK, Husemoen G, Vestergaard M, Jin L, Zhao S, Wingler LM, Rambarat PK, et al. (2018) Small-molecule positive allosteric modulators of the $\beta 2$-adrenoceptor isolated from DNA-encoded libraries. Mol Pharmacol 94:850-861.

Ballesteros JA and Weinstein H (1995) Integrated methods for the construction of three-dimensional models and computational probing of structure-function relations in G protein-coupled receptors. Methods in Neurosciences 25:366-428.

Beadle CD, Coates DA, Hao J, Krushinski JH, Reinhard MR, Schaus JM, and Wolfangel CD (2014) inventors, Eli Lilly and Company, assignee. 3,4-Dihydroisoquinolin2(1H)-yl compounds. International patent WO2014193781A1. 2014 Dec 4.

Bruns RF and Fergus JH (1990) Allosteric enhancement of adenosine A1 receptor binding and function by 2-amino-3-benzoylthiophenes. Mol Pharmacol 38:939-949.

Bruns RF, Mitchell SN, Wafford KA, Harper AJ, Shanks EA, Carter G, O'Neill MJ, Murray TK, Eastwood BJ, Schaus JM, et al. (2018) Preclinical profile of a dopamine D1 potentiator suggests therapeutic utility in neurological and psychiatric disorders. Neuropharmacology 128:351-365.

Bueno AB, Showalter AD, Wainscott DB, Stutsman C, Marín A, Ficorilli J, Cabrera O, Willard FS, and Sloop KW (2016) Positive allosteric modulation of the glucagonlike peptide-1 receptor by diverse electrophiles. J Biol Chem 291:10700-10715.

Canals M, Lane JR, Wen A, Scammells PJ, Sexton PM, and Christopoulos A (2012) A Monod-Wyman-Changeux mechanism can explain G protein-coupled receptor (GPCR) allosteric modulation. J Biol Chem 287:650-659.

Changeux J-P and Christopoulos A (2017) Allosteric modulation as a unifying mechanism for receptor function and regulation. Diabetes Obes Metab 19 (Suppl 1):4-21.

Congreve M, Oswald C, and Marshall FH (2017) Applying structure-based drug design approaches to allosteric modulators of GPCRs. Trends Pharmacol Sci 38:837-847.

Conn PJ, Lindsley CW, Meiler J, and Niswender CM (2014) Opportunities and challenges in the discovery of allosteric modulators of GPCRs for treating CNS disorders. Nat Rev Drug Discov 13:692-708.

Ehlert FJ (2005) Analysis of allosterism in functional assays. J Pharmacol Exp Ther 315:740-754

Gearing KL, Barnes A, Barnett J, Brown A, Cousens D, Dowell S, Green A, Patel K, Thomas P, Volpe F, et al. (2003) Complex chimeras to map ligand binding sites of GPCRs. Protein Eng 16:365-372.

Griffin MT, Figueroa KW, Liller S, and Ehlert FJ (2007) Estimation of agonist activity at $\mathrm{G}$ protein-coupled receptors: analysis of $\mathrm{M} 2$ muscarinic receptor signaling through Gi/o,Gs, and G15. J Pharmacol Exp Ther 321:1193-1207.

Kenakin T (2014) A Pharmacology Primer: Techniques for More Effective and Strategic Drug Discovery, 4th ed, Elsevier, San Diego, CA.

Kenakin T (2017) A scale of agonism and allosteric modulation for assessment of selectivity, bias, and receptor mutation. Mol Pharmacol 92:414-424.

Kenakin T and Christopoulos A (2013) Signalling bias in new drug discovery: detection, quantification and therapeutic impact. Nat Rev Drug Discov 12:205-216.

Koshland DE Jr, Némethy G, and Filmer D (1966) Comparison of experimental binding data and theoretical models in proteins containing subunits. Biochemistry 5:365-385.

Kruse AC, Ring AM, Manglik A, Hu J, Hu K, Eitel K, Hübner H, Pardon E, Valant C, Sexton PM, et al. (2013) Activation and allosteric modulation of a muscarinic acetylcholine receptor. Nature 504:101-106.

Lewis MA, Hunihan L, Watson J, Gentles RG, Hu S, Huang Y, Bronson J, Macor JE, Beno BR, Ferrante M, et al. (2015) Discovery of D1 dopamine receptor positive allosteric modulators: characterization of pharmacology and identification of residues that regulate species selectivity. J Pharmacol Exp Ther 354:340-349.

Liu X, Ahn S, Kahsai AW, Meng K-C, Latorraca NR, Pani B, Venkatakrishnan AJ, Masoudi A, Weis WI, Dror RO, et al. (2017) Mechanism of intracellular allosteric $\beta_{2} \mathrm{AR}$ antagonist revealed by X-ray crystal structure. Nature 548:480-484.
Luderman KD, Conroy JL, Free RB, Southall NT, Ferrer M, Aubé J, Frankowski KJ, and Sibley DR (2016) Structurally diverse positive allosteric modulators of the D1 dopamine receptor potentiate G-protein and $\beta$-arrestin-mediated signaling. FASEB J 30 (Suppl):931.

Luderman KD, Conroy JL, Free RB, Southall NT, Ferrer M, Aubé J, Lane JR, Frankowski K, and Sibley DR (2018) Positive allosteric modulators of the D1 dopamine receptor act at diverse binding sites. FASEB J 32 (Suppl):827.

Monod J, Wyman J, and Changeux J-P (1965) On the nature of allosteric transitions: a plausible model. $J$ Mol Biol 12:88-118.

Monsma FJ Jr, Mahan LC, McVittie LD, Gerfen CR, and Sibley DR (1990) Molecular cloning and expression of a D1 dopamine receptor linked to adenylyl cyclase activation. Proc Natl Acad Sci USA 87:6723-6727.

Moro O, Lameh J, Högger P, and Sadée W (1993) Hydrophobic amino acid in the i2 loop plays a key role in receptor-G protein coupling. J Biol Chem 268:22273-22276.

Nemeth EF, Steffey ME, Hammerland LG, Hung BC, Van Wagenen BC, DelMar EG, and Balandrin MF (1998) Calcimimetics with potent and selective activity on the parathyroid calcium receptor. Proc Natl Acad Sci USA 95:4040-4045.

Noetzel MJ, Rook JM, Vinson PN, Cho HP, Days E, Zhou Y, Rodriguez AL, Lavreysen H, Stauffer SR, Niswender CM, et al. (2012) Functional impact of allosteric agonist activity of selective positive allosteric modulators of metabotropic glutamate receptor subtype 5 in regulating central nervous system function. Mol Pharmacol 81: 120-133.

Nolte WM, Fortin JP, Stevens BD, Aspnes GE, Griffith DA, Hoth LR, Ruggeri RB, Mathiowetz AM, Limberakis C, Hepworth D, et al. (2014) A potentiator of orthosteric ligand activity at GLP-1R acts via covalent modification. Nat Chem Biol 10:629-631.

Oswald C, Rappas M, Kean J, Doré AS, Errey JC, Bennett K, Deflorian F, Christopher JA, Jazayeri A, Mason JS, et al. (2016) Intracellular allosteric antagonism of the CCR9 receptor. Nature 540:462-465.

Proska J and Tucek S (1994) Mechanisms of steric and cooperative actions of alcuronium on cardiac muscarinic acetylcholine receptors. Mol Pharmacol 45: 709-717.

Rasmussen SG, Choi HJ, Fung JJ, Pardon E, Casarosa P, Chae PS, Devree BT, Rosenbaum DM, Thian FS, Kobilka TS, et al. (2011a) Structure of a nanobodystabilized active state of the $\beta(2)$ adrenoceptor. Nature 469:175-180.

Rasmussen SG, DeVree BT, Zou Y, Kruse AC, Chung KY, Kobilka TS, Thian FS, Chae PS, Pardon E, Calinski D, et al. (2011b) Crystal structure of the $\beta 2$ adrenergic receptor-Gs protein complex. Nature 477:549-555.

Song G, Yang D, Wang Y, de Graaf C, Zhou Q, Jiang S, Liu K, Cai X, Dai A, Lin G, et al. (2017) Human GLP-1 receptor transmembrane domain structure in complex with allosteric modulators. Nature 546:312-315.

Stockton JM, Birdsall NJ, Burgen AS, and Hulme EC (1983) Modification of the binding properties of muscarinic receptors by gallamine. Mol Pharmacol 23: 551-557.

Svensson KA, Heinz BA, Schaus JM, Beck JP, Hao J, Krushinski JH, Reinhard MR, Cohen MP, Hellman SL, Getman BG, et al. (2017) An allosteric potentiator of the dopamine D1 receptor increases locomotor activity in human D1 knock-in mice without causing stereotypy or tachyphylaxis. J Pharmacol Exp Ther 360:117-128.

Valant C, Felder CC, Sexton PM, and Christopoulos A (2012) Probe dependence in the allosteric modulation of a $\mathrm{G}$ protein-coupled receptor: implications for detection and validation of allosteric ligand effects. Mol Pharmacol 81:41-52.

Zhang H, Qiao A, Yang D, Yang L, Dai A, de Graaf C, Reedtz-Runge S, Dharmarajan V, Zhang H, Han GW, et al. (2017) Structure of the full-length glucagon class B G-protein-coupled receptor. Nature 546:259-264.

Zheng Y, Qin L, Zacarías NV, de Vries H, Han GW, Gustavsson M, Dabros M, Zhao C, Cherney RJ, Carter P, et al. (2016) Structure of CC chemokine receptor 2 with orthosteric and allosteric antagonists. Nature 540:458-461.

Zhou Q-Y, Grandy DK, Thambi L, Kushner JA, Van Tol HHM, Cone R, Pribnow D, Salon J, Bunzow JR, and Civelli O (1990) Cloning and expression of human and rat D1 dopamine receptors. Nature 347:76-80.

Address correspondence to: Dr. Beverly A. Heinz, Lilly Research Laboratories, Eli Lilly \& Co., Lilly Corporate Center, Indianapolis, IN 46285. E-mail: heinz_beverly_a@lilly.com 